[Michael J. Papageorge, Christoph Arndt, Frederik Fuest, Wolfgang Meier, Jeffrey A. Sutton, Highspeed mixture fraction and temperature imaging of pulsed, turbulent fuel jets auto-igniting in hightemperature, vitiated co-flows, Experiments in Fluids 55 (2014), 1763.]

The original publication is available at www.springerlink.com

http://dx.doi.org/10.1007/s00348-014-1763-z 


\title{
High-Speed Mixture Fraction and Temperature Imaging of Pulsed, Turbulent Fuel Jets Auto-Igniting in High-Temperature, Vitiated Co-Flows
}

\author{
Michael J. Papageorge ${ }^{\mathrm{a}}$, Christoph Arndt ${ }^{\mathrm{b}}$, Frederik Fuest ${ }^{\mathrm{a}}$, Wolfgang Meier ${ }^{\mathrm{b}}$, Jeffrey A. Sutton ${ }^{\mathrm{a}, 1}$, \\ ${ }^{a}$ Department of Mechanical and Aerospace Engineering, Ohio State University, Columbus, OH, USA \\ ${ }^{\mathrm{b}}$ German Aerospace Center (DLR), Institute of Combustion Technology, Stuttgart, Germany
}

\begin{abstract}
In this manuscript we describe an experimental approach to simultaneously measure high-speed image sequences of the mixture fraction and temperature fields during pulsed, turbulent fuel injection into a high-temperature, co-flowing, and vitiated oxidizer stream. The quantitative mixture fraction and temperature measurements are determined from $10-\mathrm{kHz}$-rate planar Rayleigh scattering and a robust data processing methodology which is accurate from fuel injection to the onset of auto-ignition. In addition, the data processing is shown to yield accurate temperature measurements following ignition to observe the initial evolution of the "burning" temperature field. High-speed $\mathrm{OH}^{*}$ chemiluminescence (CL) was used to determine the spatial location of the initial auto-ignition kernel. In order to ensure that the ignition kernel formed inside of the Rayleigh scattering laser light sheet, $\mathrm{OH}^{*} \mathrm{CL}$ was observed in two viewing planes, one near-parallel to the laser sheet and one perpendicular to the laser sheet. The highspeed laser measurements are enabled through the use of the unique high-energy pulse burst laser system (HEPBLS) which generates long-duration bursts of ultra-high pulse energies at $532 \mathrm{~nm}$ (>1 Joule) suitable for planar Rayleigh scattering imaging. A particular focus of this study was to characterize the fidelity of the measurements both in the context of the precision and accuracy, which includes facility operating and boundary conditions and measurement signal-to-noise (SNR). The mixture fraction and temperature fields deduced from the high-speed planar Rayleigh scattering measurements exhibited SNR values greater than 100 at temperatures exceeding $1300 \mathrm{~K}$. The accuracy of the measurements was determined by comparing the current mixture fraction results to that of "cold", isothermal, non-reacting jets. All profiles, when properly normalized exhibited self-similarity and collapsed upon one another. Finally, example mixture fraction, temperature, and $\mathrm{OH}^{*}$ emission sequences are presented for a variety for fuel and vitiated oxidizer combinations. For all cases considered, auto-ignition occurred at the periphery of the fuel jet, under very "lean" conditions, where the local mixture fraction was less than the stoichiometric mixture fraction $\left(\xi<\xi_{\mathrm{s}}\right)$. Furthermore, the ignition kernel formed in regions of low scalar dissipation rate, which agrees with previous results from direct numerical simulations.
\end{abstract}

\footnotetext{
${ }^{1}$ Corresponding author: (614)688-4999; email: sutton.235@osu.edu
} 


\section{Introduction}

The mixing and subsequent auto-ignition of a (cold) turbulent fuel stream issuing into a hot oxidizing environment is of significant interest due to its importance in a number of engineering systems. Internal combustion engines including diesel or HCCI platforms, energy-conversion systems employing flameless or reheat combustion, and scramjets are examples where auto-ignition is necessary to initiate combustion. Conversely, auto-ignition is to be prevented in spark-ignited (SI) engines, flammable material storage areas, and the mixing ducts of gas turbine combustors in order to avoid catastrophic combustor damage or excessively high levels of pollutant output [1]. In addition, for flows with high levels of swirl and flow re-circulation or scramjet applications with flameholders, auto-ignition can play an important role in the continuous flame stabilization mechanism [e.g., 1, 2].

The physical and chemical processes governing auto-ignition under turbulent fuel injection are complex involving a coupling of turbulent fluid mechanics, scalar mixing of inhomogeneous reactants, and finite-rate kinetics, where the particular chemistry responsible for auto-ignition occurs on a similar time scale as the turbulence. In this manner, experimental characterization of the auto-ignition phenomena is quite challenging. The majority of previous experimental work has focused on stablyburning flames which result from auto-ignition, where the primary experimental setup has involved continuously-fed fuel jets issuing in hot air [e.g., 3, 4] or vitiated combustion products [e.g., 5-8] (jet-inhot-coflow, JHC). For example, Cabra et al. [5, 6] used point-based Raman/Rayleigh/laser-induced fluorescence measurements within nitrogen-diluted hydrogen and methane fuels issuing into vitiated coflows $(\mathrm{T}=1045 \mathrm{~K}-1350 \mathrm{~K})$ to investigate the general structure of the stable, lifted flames. The measured peak temperatures (indicating heat release), conditioned on mixture fraction, occurred at very lean $\left(\xi<\xi_{\mathrm{s}}\right)$ mixtures for the upstream positions, evolving to $\xi=\xi_{\mathrm{s}}$ at downstream locations. Gordon et al. [7,8] used low-repetition-rate, planar imaging of temperature, $\mathrm{CH}_{2} \mathrm{O}$, and $\mathrm{OH}$ in a very similar configuration to that of Cabra et al. [5,6] to examine the structure of individual ignition kernels upstream of stably-burning flames resulting from natural gas issuing into a vitiated co-flow. The imaging results indicated isolated ignition kernels, inferred from temperature and $\mathrm{CH}_{2} \mathrm{O}$ increases, which were not always 
accompanied by $\mathrm{OH}$ and which occurred in regions of low temperature gradients, indicating auto-ignition (and not flame propagation) was a primary mechanism governing the lifted flame stabilization.

Auto-ignition of a turbulent fuel jet issuing into a hot coflow is highly transient, occurs on a short time scale and is a non-statistically-stationary process that is ideally suited for high-acquisition-rate measurements. With the advancements in high-speed optical and laser diagnostics, investigations of autoignition dynamics have been reported recently [e.g., 9-14]. Sadanandan et al. [9] investigated the transient ignition of near-stoichiometric hydrogen/air mixtures by hot exhaust gas jets using high-speed Schlieren and $\mathrm{OH}$ planar laser-induced fluorescence (PLIF). Results indicated that ignition occurred near the tip of the exhaust-gas jet as opposed to the high-strain regions within the lateral sides of the jet. Fast et al. [10] observed the auto-ignition of transient injection of gaseous dimethyl ether (DME) under highpressure conditions. Using high-speed $(10-\mathrm{kHz})$ shadowgraphy, two-stage ignition was observed for the reported operating conditions. Oldenhof et al. [11] studied the ignition of impulsively-started natural gas jets into hot coflows using 10-kHz particle imaging velocimetry (PIV) and flame chemiluminescence, where the flow initially existed the injector under laminar-like conditions followed by a sudden transition to a turbulent phase after a few milliseconds. No combustion occurred during the laminar phase and following the transition to the turbulent phase, ignition delay times were much longer than necessitated by the jet fluid mechanic or auto-ignition chemistry time scales. In addition flame structures were only noted in regions where the velocity was close to that of the hot coflow suggesting that the transport of the coflow fluid into the jet periphery governs the auto-ignition time.

Of particular note in relationship to this manuscript are the recent high-speed OH PLIF and OH emission imaging results of Arndt et al. [12-14] from pulsed methane jets issuing into hot, vitiated coflows. A particular feature of these studies was the use of a JHC facility with well-defined and repeatable boundary conditions. This is an important facet as the auto-ignition process is very sensitive to boundary conditions including temperature, species concentrations, and $\mathrm{O}_{2}$ concentration, as well as flow properties including strain rate and scalar dissipation rate. From these works, auto-ignition times (relative to fuel injection) were estimated and the downstream locations of the first ignition kernels were determined from 
the kHz-rate imaging for a range of co-flow temperatures. From the high-speed OH PLIF imaging, it was suggested that the local mixing rates may have a strong influence on ignition locations.

While all of the aforementioned studies yielded new insight and statistics of auto-ignition time and location in turbulent flow fields, no information was available concerning the roles of turbulence and turbulent mixing, including the reason for the observed ignition location intermittency. As described in a recent review by Mastorakos [1], direct numerical simulation (DNS) results using both simplified [e.g., 15-19] and complex chemistry [e.g., 20-22] have shown that auto-ignition occurs away from the stoichiometric mixture fraction $\left(\xi_{\mathrm{s}}\right)$ and at a location referred to as the "most reactive mixture fraction", $\xi_{\mathrm{MR}}$. Considering the case of cold fuel injection into a hot oxidizer stream, very lean mixtures yield high temperatures but low fuel concentration. As $\xi$ increases, the temperature decreases, but the fuel concentration increases. Conceptually, these two effects are in competition resulting in an optimal composition which yields a maximum reaction rate (or "fastest" auto-ignition time) and hence the initial ignition event. The mixture fraction corresponding to this composition (and temperature) is denoted as $\xi_{\mathrm{MR}}$. Recent DNS work under turbulent fuel injection have shown that not all regions with $\xi=\xi_{\mathrm{MR}}$ ignite simultaneously [23]; that is the auto-ignition process is intermittent, which has been confirmed by the high-speed imaging results of Arndt et al. $[13,14]$. DNS results have suggested that scalar dissipation rate $(\chi)$ fluctuations are very important in determining the probability of ignition and that the first regions to auto-ignite are the ones experiencing low values of $\chi$ [e.g., 20-22, 24], perhaps corresponding to the cores of vortices [e.g., 15, 19, 25]. To investigate the roles of molecular and thermal mixing and mixing rates on auto-ignition, new experimental tools are needed to measure the mixture fraction $(\xi)$ and temperature fields prior to and through the onset of auto-ignition with sufficient spatial and temporal resolution to capture the governing dynamics.

In this manuscript we describe an experiment to simultaneously measure two-dimensional mixture fraction, temperature, and $\mathrm{OH}^{*}$ emission (indicating ignition kernel formation) fields from a pulsed fuel jet auto-igniting in a co-flowing stream of hot, vitiated combustion products. The use of the high-energy 
pulse burst laser system (HEPBLS) [26, 27], which produces long-duration bursts of ultra-high energy output at $532 \mathrm{~nm}$, allows high-speed $(10-\mathrm{kHz})$ planar Rayleigh scattering imaging and the simultaneous determination of the mixture fraction and temperature fields from the start of fuel injection through the onset of ignition. The high-speed laser and optical measurements are carried out in the well-characterized and highly-repeatable DLR JHC facility [13, 14], which enables systematic investigations of the autoignition process. The particular focus of the current paper is the fidelity of the measurements, which includes the combined effects of the DLR JHC facility operating/boundary conditions, the signal-to-noise ratio of the high-speed measurements, and the accuracy of a new data processing methodology. Example image sequences are shown for various fuel and "hot" oxidizer combinations highlighting aspects of the observed auto-ignition dynamics and providing a necessary starting point for subsequent detailed studies investigating the transient chemistry and physics governing auto-ignition.

\section{Experimental Approach}

\subsection{High-Energy Pulse Burst Laser System (HEPBLS)}

A schematic of the high-energy pulse burst laser system (HEPBLS) is shown in Fig. 1. The details of the laser system have been reported previously in $[26,27]$; however certain changes to the laser configuration were made for the current experiment as described below. The HEPBLS was designed to produce a unique combination of high repetition rates and high pulse energies over long pulse burst durations (high average power) for quantitative time-resolved imaging of turbulence and combustion dynamics, specifically enabling "low-signal" measurements such as planar Rayleigh scattering imaging [e.g., 27-29], spontaneous 1D Raman scattering imaging [30], and planar laser-induced fluorescence (PLIF) imaging [31,32] to be extended to kHz-rate imaging. The HEPBLS is a master oscillator, power amplifier (MOPA) system that amplifies the low-energy output $(\sim 10 \mu \mathrm{J} /$ pulse $)$ of a continuously running narrowlinewidth $\mathrm{Nd}: \mathrm{YVO}_{4}$ laser (master pulsed oscillator, $\mathrm{PO}$ ) in a series of six, long-duration, flashlamppumped Nd:YAG amplifier stages with total system gain $>1 \times 10^{5}$. The repetition rate of the pulsed oscillator determines the pulse spacing within the burst, while the flashlamp-discharge duration 
determines the overall length of the burst and the number of amplified pulses. In the current manuscript, all results are reported at $10 \mathrm{kHz}(100 \mu$ s pulse spacing).

The continuous train of 1064-nm pulses from the PO is first amplified in a series of two doublepass, dual-flashlamp-pumped amplifier stages (AMP 1 and AMP2) with 4-mm- and 6.35-mm-diameter $\mathrm{Nd}$ :YAG rods, respectively. At $10 \mathrm{kHz}$, the gain through the first two amplifier stages is $>1 \times 10^{4}$ resulting in 1064-nm pulse output energies $~ 200 \mathrm{~mJ} /$ pulse. It is noted that the output of each amplifier stage is "imaged" onto the exit plane of the subsequent amplifier stage through relay imaging optics [33]. Each relay stage consists of a set of lens pairs that focus the beam through a diamond pinhole, which serves as a low-pass spatial filter, and re-collimates the light at a desired magnification. By incorporating image relay optics, diffraction, birefringence, and thermal lensing effects are controlled at each stage in order to preserve high beam quality. After two stages of amplification, the pulse train is focused into a stimulated Brillouin scattering-phase conjugate mirror (SBS-PCM) and retro-reflected towards AMP3. The SBS-PCM, as described in [26, 34], is implemented as a pre-cautionary measure to stop the growth of Amplified Spontaneous Emission (ASE), which grows exponentially with gain. When the incident laser beam intensity is above a minimum SBS threshold it is coherently retro-reflected, while anything below that threshold (e.g. incoherent ASE) passes through the cell to a beam dump.

As reported in Ref. 26, the HEPBLS is designed to be a dual-leg system by passing the output from the PCM through 50/50 beam splitter and amplifying the two parallel pulse trains in three identical sets of amplification stages. In this manner, two sets of output pulse trains are available for multiparameter diagnostics. For the current experiment, the HEPBLS is operated in a single-output-leg configuration, where the beamsplitter is replaced by a single mirror and the pulse train from the PCM is sent to AMP3 (9.5-mm-diameter Nd:YAG rod), which is arranged in a double-pass arrangement. Amplification stages 4-6, which use 19.5-mm-diameter Nd:YAG rods are operated in a single pass configuration with a 90-degree quartz rotator placed between stages 4 and 5 to help reduce thermallyinduced birefringence effects caused by the thermal gradients within the rods. The output of the sixth and final amplifier stage is approximately 2 Joule/pulse at $1064 \mathrm{~nm}$ at $10 \mathrm{kHz}$. Finally, the fundamental 
output passes through a single $12 \times 12 \times 20 \mathrm{~mm}^{3}$ type I LBO for second harmonic generation of $532 \mathrm{~nm}$. Figure 2 shows an example pulse energy trace at $10 \mathrm{kHz}$ for a duration of 20 milliseconds without AMP6. Following the addition of AMP 6 532-nm output pulse energies exceeded 1 Joule/pulse for burst lengths as long as 230 pulses.

\subsection{Imaging and Optical System}

Figure 3 a shows a schematic of the imaging system used for the auto-ignition experiments. The 532-nm, vertically-polarized output of the HEPBLS is formed into a 15-mm-tall laser sheet by using a single 750$\mathrm{mm}$ focal length, plano-convex cylindrical lens. The laser sheet thickness, reported as the $1 / \mathrm{e}^{2}$ value, has been measured as $<300 \mu \mathrm{m}$ both by rotating the cylindrical lens 90 degrees and imaging Rayleigh scattering from ambient air and by replacing the cylindrical lens by a 750-mm focal length spherical lens and imaging Rayleigh scattering from the focused 1D line in ambient air. The high-energy 532-nm output is used for high-speed planar Rayleigh scattering imaging as discussed in Sec. 3.1. The Rayleigh scattering signal from the DLR JHC and from an additional uniform air coflow (used for laser-sheet intensity and pulse energy fluctuation corrections) is imaged by a pair of high-speed CMOS cameras (Vision Research, Phantom V711). Figure 3b shows a photograph of the DLR JHC and uniform air coflow in relationship to the HEPBLS 532-nm laser pulse train.

The Rayleigh scattering from the DLR JHC is collected and focused down onto the "Rayleigh Camera" by the combination of a 100-mm-diameter, 240-mm focal length achromat lens and an $85-\mathrm{mm}$ $f / 1.4$ camera lens. The combination of the achromat and camera lens is used to maximize light collection at the desired magnification $(\sim 0.4)$, where the imaged area is approximately $55 \times 55 \mu \mathrm{m}^{2} /$ pixel. The Rayleigh scattering from the uniform air coflow is collected and focused down onto the "Sheet Correction Camera" with an 85-mm $f / 1.4$ camera lens. As noted from Fig. 3a, the "Sheet Correction Camera" is not aligned normal to the laser sheet (due to space limitations), thus only one portion of the field-of-view (FOV) is in focus. This region of the FOV is carefully mapped out and used for the laser sheet intensity 
corrections. At 10,000 frames/second, the CMOS cameras operate with a resolution of 1152 x 664 pixels or a field-of-view of approximately $63 \mathrm{~mm}$ x $36 \mathrm{~mm}$.

$\mathrm{OH}$ chemiluminescence $\left(\mathrm{OH}^{*} \mathrm{CL}\right)$ was collected using two intensified CMOS cameras (Photron SA5 + LaVision HS-IRO) coupled to $100-\mathrm{mm}$ f/2.8 Cerco UV camera lenses and high-transmission bandpass filters (> 80\% transmission at $310 \mathrm{~nm}$ ). Due to space limitations, the first $\mathrm{OH}^{*}$ emission camera $\left(\mathrm{OH}^{*} \mathrm{CL}\right.$ Camera 1) was configured at 15 degrees from normal to the incident laser sheet and the planar Rayleigh scattering FOV with a magnification of 0.28 or $72 \mu \mathrm{m} /$ pixel. This camera was used to determine the onset of auto-ignition and the downstream location of the ignition kernel formation. The second $\mathrm{OH}^{*} \mathrm{CL}$ Camera 2 was positioned at an angled-offset end view to image a FOV along the laser sheet to determine the formation of an ignition kernel relative to the laser sheet used for planar Rayleigh scattering. The post-processing of the $\mathrm{OH}^{*} \mathrm{CL}$ images has been described in detail in $[13,14]$ and will not be discussed in this manuscript as the $\mathrm{OH}^{*}$ emission data is used only to select datasets where ignition occurred within the probe volume defined by the laser sheet. Only image sequences in which the initial kernel (as defined by $\mathrm{OH}^{*} \mathrm{CL}$ ) formed within the laser sheet were included in the data analysis and results presented in Sections 3 and 4.

\subsection{DLR Jet-in-Hot-Coflow(JHC) and Operating Conditions}

Figure 4 shows a schematic of the DLR Jet-in-Hot-Coflow (DLR JHC) burner used for this experiment. The hot, vitiated coflow is generated by stabilizing a lean, premixed hydrogen/air flame on the $75 \mathrm{~mm} \mathrm{x}$ $75 \mathrm{~mm}$, water-cooled bronze sintered matrix. The co-flow temperature (and $\mathrm{O}_{2}$ concentration) is controlled by varying the equivalence ratio of the premixed hydrogen/air flame. The flow rates of the reactants were controlled with Brooks MFC 5850 mass flow controllers and monitored with coriolis flow meters (Siemens Sietrans Mass 2100) with a manufacturer's stated accuracy of $<1.5 \%$, resulting in a maximum uncertainty in the co-flow equivalence ratio of $\pm 3 \%$ 
To minimize heat losses to the burner matrix, the flow rates are operated such that the velocity of the hot co-flow was $4 \mathrm{~m} / \mathrm{s}$ [35]. The operating conditions considered in this experiment are shown in Table 1, along with the adiabatic flame temperature $\left(\mathrm{T}_{\mathrm{ad}}\right)$, the experimentally-determined co-flow temperatures $\left(\mathrm{T}_{\mathrm{ox}}\right)$, and the calculated equilibrium product gas composition for a given equivalence ratio with temperature $\mathrm{T}_{\mathrm{ox}}$. The details of the procedure for determining $\mathrm{T}_{\mathrm{ox}}$ are given in Sec. 3.2. The hot co-flow is surrounded by two quartz windows (parallel to the laser sheet direction) to minimize the effect of ambient temperature and particulate fluctuations. Entrance and exit windows normal to the laser sheet were not used due to the high laser pulse energies from the HEPBLS and the resulting high laser intensities due to the proximity of the windows to the focal plane of the laser sheet. Without the entrance and exit windows, air entrainment effects were first noted at an axial position of $x / d=25$, where $d$ is the nozzle diameter for radial positions of $r / d>12$ and at $x / d=30$ for $r / d>10$. At $x / d=30$, the periphery of the jet is confined to radial positions of $\mathrm{r} / \mathrm{d}<5$. In this manner, the jet-coflow interface is unaffected by any air entrainment effects. Furthermore, as shown in Sec. 4.3, the auto-ignition events occur at axial positions of $\mathrm{x} / \mathrm{d}=20$ for the current test conditions, were no air entrainment was noted for any radial positions.

Pulsed fuel jets were injected into the hot coflow through a 2 -mm-diameter nozzle mounted $8 \mathrm{~mm}$ above the surface of the co-flow burner matrix. The operating conditions of the fuel jets (at steady-state conditions) are reported in Table 1 . The fuel pulses were controlled using a 2/2 way solenoid valve (Staiger VA204-5), located 125 tube diameters below the nozzle exit to ensure fully-developed pipe flow at the injection location. The duration of the fuel injection can be varied from less than 2 ms to continuous operation, although no ignition dependence on injection duration has been noted for valve opening times greater than $3 \mathrm{~ms}$ [12]. In the current experiment, the solenoid valve was opened for 55 $\mathrm{ms}$, which is more than sufficient for auto-ignition $(\sim 2 \mathrm{~ms})$ and the establishment of a stably-burning flame $(<4 \mathrm{~ms})$ [12-14], but short enough to minimize any influence of burner heating for subsequent measurement bursts. It is noted that the pulsed fuel injection is highly reproducible. The physical penetration of the jet tip for methane injection has been measured in the near-field of the jet $(5<\mathrm{x} / \mathrm{d}<$ 
10). Results indicate that the standard deviation of the jet tip position over 50 measurement burst is $<1$ $\mathrm{mm}$. Since the jet penetration distance is directly proportional to time in the near-field of a jet [36], this spatial uncertainty for a 100-m/s injection velocity corresponds to a temporal uncertainty of less than 10 $\mu \mathrm{s}$ in the repeatability of the fuel injection.

\section{Data Reduction Methodology}

\subsection{Planar Rayleigh Scattering}

Laser Rayleigh scattering is a non-intrusive diagnostic technique that describes the elastic scattering from atoms and molecules whose effective diameter is much less than the wavelength of the incident laser light. The total collected Rayleigh scattering signal can be written as

$$
S_{R A Y}=A I_{o} n \sigma_{m i x}
$$

where $A$ is a constant describing collection volume and efficiency of the optical setup, $I_{o}$ is the incident laser intensity, $n$ is the number density, $\sigma_{m i x}$ is the mixture-averaged differential Rayleigh scattering

cross-section defined as $\sigma_{m i x}=\sum_{i=1}^{N} X_{i} \sigma_{i}$, and $X_{i}$ and $\sigma_{i}$ are the mole fraction and differential scattering cross-section of species $i$, respectively. As noted in Eq. (1), the local Rayleigh scattering signal depends on both the gas number density and the local mixture-averaged Rayleigh scattering cross section, which, in general, is a function of the local composition.

Previously, high-speed planar Rayleigh scattering-based mixture fraction imaging in turbulent nonreacting jets [27, 28] and temperature imaging in turbulent non-premixed jet flames [27, 29] has been performed using the HEPBLS. For the previous non-reacting jet studies, neither the temperature nor the pressure varied within the flowfield yielding a Rayleigh scattering signal which is proportional to the local mixture-averaged Rayleigh scattering cross section (or composition), thus enabling a direct measurement of the mixture fraction field. For the previous temperature imaging, the flame composition ("DLR" $\mathrm{CH}_{4} / \mathrm{H}_{2} / \mathrm{N}_{2}[37,38]$ ) was chosen such that the Rayleigh scattering cross-section is nearly constant 
across composition space and the local Rayleigh scattering signal is proportional to the local number density, thus enabling a direct measurement of the temperature field under isobaric conditions. In this manuscript we present a methodology to deduce the temporally-evolving mixture fraction and temperature fields simultaneously for the case of a "cold" turbulent fuel issuing into a "hot" oxidizer stream from fuel injection to auto-ignition using high-speed planar Rayleigh scattering.

\subsection{Determination of Co-Flow Conditions}

The equivalence ratio of the reactants of the coflow is set to within the accuracy of the flow meters. For a given equivalence ratio, the true co-flow temperature $\left(\mathrm{T}_{\mathrm{ox}}\right)$ will be lower than the adiabatic flame temperature $\left(\mathrm{T}_{\mathrm{ad}}\right)$ due to heat losses to the burner matrix surface and additional minor radiation losses [e.g., 39]. Planar Rayleigh scattering was applied to the product gases of the hydrogen/air flame to experimentally determine the temperature of the vitiated oxidizer co-flow in conjunction with an iterative data reduction procedure with the assumption that the equivalence ratio was a known value. First, $\mathrm{T}_{\mathrm{ad}}$ and the mole fractions of the major product species $\left(\mathrm{N}_{2}, \mathrm{O}_{2}\right.$, and $\left.\mathrm{H}_{2} \mathrm{O}\right)$ were calculated for the set equivalence ratio using the NASA Chemical Equilibrium with Applications (CEA) code [40]. Using the calculated species mole fractions, a guess of the mixture-averaged Rayleigh scattering cross section of the hot oxidizing co-flow is calculated as $\sigma^{\prime}{ }_{\mathrm{ox}}=\mathrm{X}_{\mathrm{N} 2} \sigma_{\mathrm{N} 2}+\mathrm{X}_{\mathrm{O} 2} \sigma_{\mathrm{O} 2}+\mathrm{X}_{\mathrm{H} 20} \sigma_{\mathrm{H} 2 \mathrm{O}}$. In addition, $\mathrm{T}_{\mathrm{ad}}$ is taken as the initial guess of the temperature of the oxidizer co-flow, $\mathrm{T}^{\prime}{ }_{\mathrm{ox}}=\mathrm{T}_{\mathrm{ad}}$. Using Eq. (1), the measured Rayleigh scattering signal of the co-flow, when normalized by a reference measurement from room-temperature air, $\mathrm{S}_{\text {ox }} / \mathrm{S}_{\text {air }}$, is compared to $\mathrm{S}{ }_{\text {ox }} / \mathrm{S}_{\text {air }}=\mathrm{T}_{\text {air }} / \mathrm{T}^{\prime}{ }_{\text {ox }}{ }^{*} \sigma^{\prime}{ }_{\text {ox }} / \sigma_{\text {air }}$. If the two terms are equivalent, then $\mathrm{T}_{\mathrm{ox}}=\mathrm{T}_{\mathrm{ad}}$. However, as mentioned previously, a small amount of heat loss is expected. In this manner, the temperature and mole fractions are iterated upon by reducing $\mathrm{T}^{,}{ }_{\mathrm{ox}}<\mathrm{T}_{\mathrm{ad}}$ and re-calculating the major product species using CEA for a temperature equal to $\mathrm{T}^{\prime}{ }_{\text {ox }}$ (non-adiabatic conditions). For each new temperature guess and corresponding calculated mole fractions of $\mathrm{N}_{2}, \mathrm{O}_{2}$, and $\mathrm{H}_{2} \mathrm{O}$, a new guess of $\sigma_{\text {ox }}$, and $\mathrm{S}^{\prime}{ }_{\text {ox }} / \mathrm{S}_{\text {air }}$ is generated. The assumed temperature of the co-flow $\left(\mathrm{T}^{\prime}{ }_{\text {ox }}\right)$ is iterated upon until $\mathrm{S}_{\text {ox }} / \mathrm{S}_{\text {air }}=$ 
$\mathrm{S}^{\prime}{ }_{\text {ox }} / \mathrm{S}_{\text {air }}$ to within a tolerance of $0.4 \%$, which is approximately $5 \mathrm{~K}$ for the coflow conditions listed in Table 1 . The $0.4 \%$ tolerance was selected to nominally match the precision limitation imposed by noise for our best test condition ( $\left.\mathrm{SNR} \sim 200, \mathrm{~T}_{\mathrm{ox}}=1270 \mathrm{~K}\right)$ as discussed in Sec. 4.1.

Beyond measurement noise, the primary uncertainty in this approach involves the assumption of a known equivalence ratio within the coflow. Since the equivalence ratio of the reactants in the coflow is subject to a maximum uncertainty of $\pm 3 \%$ based on the uncertainty of the flow meters, there is a corresponding uncertainty in the mole fractions of the major product species used to calculate the mixture-averaged Rayleigh scattering cross section of the hot oxidizing co-flow. However, for a $\pm 3 \%$ change in equivalence ratio, the combustion products change very little and the mixture-averaged Rayleigh scattering cross section changes by a maximum of $0.1 \%$ for all cases considered in Table 1 , which introduces an additional uncertainty of $<1.5 \mathrm{~K}$.

\subsection{Simultaneous Determination of Mixture Fraction and Temperature}

Prior to auto-ignition, the system under consideration is a two-stream mixing problem between the cold fuel and the hot, vitiated oxidizer stream. In this manner, the state of mixing between the two streams is described by the mixture fraction which can be defined as

$$
\xi=Y_{f}=\frac{X_{f} W_{f}}{X_{f} W_{f}+\left(1-X_{f}\right) W_{o x}}
$$

where $Y_{f}, X_{f}$ and $W_{f}$ are the mass fraction, mole fraction, and molecular weight of the fuel, respectively, and $\mathrm{W}_{\mathrm{ox}}$ is the molecular weight of the vitiated, oxidizer stream. The oxidizer stream is composed of known combustion products $\left(\mathrm{N}_{2}, \mathrm{O}_{2}\right.$, and $\left.\mathrm{H}_{2} \mathrm{O}\right)$ from the lean, premixed $\mathrm{H}_{2}$-air flame serving as the coflow as described in Sec. 3.2. For the two-stream mixing case of cold fuel into hot oxidizer, the mixtureaveraged differential Rayleigh scattering cross section (see Eq. 1) is written as $\sigma_{\text {mix }}=X_{\mathrm{f}} \sigma_{\mathrm{f}}+\left(1-\mathrm{X}_{\mathrm{f}}\right) \sigma_{\mathrm{ox}}$, where $\sigma_{\mathrm{f}}$ is the differential Rayleigh scattering cross-section of the fuel and $\sigma_{\mathrm{ox}}$ is the differential Rayleigh scattering cross-section of the hot, vitiated oxidizer stream. Normalizing Eq. (1) by the Rayleigh 
scattering signal from a known reference condition such as air $\left(\mathrm{S}_{\mathrm{air}}\right)$ at ambient conditions $\left(\mathrm{T}_{\mathrm{air}}=300 \mathrm{~K}\right)$, the fuel mole fraction $\left(\mathrm{X}_{\mathrm{f}}\right)$ can be related to the measured Rayleigh scattering signal $\left(S_{R A Y}\right)$ by

$$
X_{f}=\left(\frac{T}{T_{a i r}} \frac{S_{R A Y}}{S_{a i r}} \frac{\sigma_{a i r}}{\sigma_{o x}}-1\right)\left(\frac{\sigma_{f}}{\sigma_{o x}}-1\right)^{-1}
$$

Note that in Eq. (3), all quantities are known or measured values except for the local temperature, T.

In order to determine the coupled quantities $\mathrm{T}$ and $\mathrm{X}_{\mathrm{f}}$, we will first consider Fig. 5, which shows the relationship between the local temperature and the fuel mole fraction for adiabatic mixing (heat transfer only through mass transfer) of cold fuel issuing into a hot, oxidizer stream for the various fuel and oxidizer combinations listed in Table 1. In Fig. 5, the ordinate is presented as a "normalized" temperature to account for varying co-flow temperatures of the experimental cases shown in Table 1. A value of "1" represents the hot co-flow temperature $\left(\mathrm{T}_{\mathrm{ox}}\right)$ shown in Table 1 for the different operating conditions and a value of " 0 " represents the cold, fuel at $T_{f}=300 \mathrm{~K}$. If the fuel issuing from the nozzle is at temperature $T_{f}$ and the oxidizer stream is at a temperature $\mathrm{T}_{\mathrm{ox}}$, then enthalpy conservation allows the local temperature, $\mathrm{T}$, which results from the mixing of the two streams to be related to the local fuel mole fraction, $\mathrm{X}_{\mathrm{f}}$ through the relationship

$$
X_{f}=\frac{\int_{T}^{T_{o x}} C_{p, o x}(T) d T}{\int_{T}^{T_{o x}} C_{p, o x}(T) d T-\int_{T_{f}}^{T} C_{p, f}(T) d T}
$$

where $C_{p, o x}(T)$ and $C_{p, f}(T)$ are the temperature-dependent molar specific heats at constant pressure for the oxidizer and fuel streams, respectively. Functionally, Eq. (4) can be considered of the form

$$
T=T_{o x}+\left(T_{f}-T_{o x}\right)\left(X_{f}+\Pi\right)
$$

where $\Pi$ describes the non-linearity in $\mathrm{X}_{\mathrm{f}}$ resulting from the difference in temperature-dependent sensible enthalpy $\left(\int C_{p, i}(T) d T\right)$ changes under calorically-imperfect conditions between the fuel and oxidizer streams. This approach is similar to that proposed by Espey et al. [41] in evaporating diesel jets with differences being that in the present work, only gas-phase processes are considered and uncertainties 
resulting from transient evaporation processes (and the energy exchange associated with the latent heat of vaporization) are not present. In addition, the current work considers enthalpy conservation in terms of extensive (molar) properties, where the non-linearity between $\mathrm{T}$ and $\mathrm{X}_{\mathrm{f}}$ is reduced as compared to massbased properties.

In Fig. 5, the 'dashed' line represents the case where $\Pi=0$, which is the case in which the fuel and oxidizer have the same $\mathrm{C}_{\mathrm{p}}(\mathrm{T})$ values. As seen in Fig. 5, for hydrocarbon fuels, the consideration of variable $C_{p}(T)$ values and the proper calculation of the change in sensible enthalpy for the different fuel and oxidizer streams is quite important. For each of the operating cases considered (Table 1), the relationship between $X_{f}$ and $T$ is determined from Eq. (4) and used in conjunction with Eq. (3) to simultaneously determine $\mathrm{X}_{\mathrm{f}}$ and $\mathrm{T}$ for any measured $\mathrm{S}_{\mathrm{RAY}} / \mathrm{S}_{\mathrm{air}}$ value with known reference conditions, $\mathrm{T}_{\text {air }}$ and $\sigma_{\text {air }}$ and boundary conditions of $\mathrm{T}_{\mathrm{f}}, \mathrm{T}_{\mathrm{ox}}$, and $\sigma_{\mathrm{ox}}$. Once $\mathrm{X}_{\mathrm{f}}$ is calculated at any point in space and time, the mixture fraction, $\xi$, is calculated from Eq. (2)

\subsection{Potential Effects of Pre-Ignition Fuel Pyrolysis and Oxidation}

The primary assumption embedded in the data reduction methodology described by Eqs. (2) - (4) is that the system is described by a two-stream mixing problem and no significant chemical reaction between the transient fuel and the high-temperature oxidizer stream occurs prior to auto-ignition. It is true that the mixing between the fuel and "hot" oxidizer streams will result in chemically-active mixtures over some regions within the flow field; however, it is imperative to note that the pyrolysis and oxidation reactions occurring at temperatures bounded by $\mathrm{T}_{\mathrm{f}}$ and $\mathrm{T}_{\mathrm{ox}}$ require a finite chemical residence time $\left(\tau_{\mathrm{c}}\right)$ that may be much longer than the local fluid mechanic time scales $\left(\tau_{\mathrm{f}}\right)$. Assuming that $\tau_{\mathrm{c}} \gg \tau_{\mathrm{f}}$, the methodology presented in Sec. 3.3 is not affected by chemical reactions and the conversion of the parent fuel to smaller hydrocarbon species. 
To assess the potential effects of chemical reaction, a series of plug flow reactor $(\mathrm{PFR})^{2}$ simulations were performed for the fuel and oxidizer combinations listed in Table 1 over the full range of mixing/temperature conditions $\left(0<\xi<1 ; \mathrm{T}_{\mathrm{ox}}>\mathrm{T}>\mathrm{T}_{\mathrm{f}}\right)$ and a broad range of residence times $\left(0<\tau_{\mathrm{R}}<\right.$ $100 \mathrm{~ms}$ ). Results from three of the five fuel/oxidizer combinations are shown in Fig. 6 using Chemkin software [42] and full chemical reaction mechanisms appropriate for $\mathrm{CH}_{4}$ and $\mathrm{C}_{3} \mathrm{H}_{8}$ [43] and dimethyl ether [44]. Figure 6 shows a contour map of $X_{\text {fuel }} / X_{\text {fuel,o }}$ as function of local mixture fraction $(\xi)$ and PFR residence time $\left(\tau_{R}\right)$, where $X_{\text {fuel }}$ is the fuel mole fraction at a given $\xi$ and $\tau_{R}$ and $X_{\text {fuel,o }}$ is the fuel mole fraction at a given $\xi$ (according to Eq. (2)) at $\tau_{\mathrm{R}}=0$. A value of $\mathrm{X}_{\text {fuel }} / \mathrm{X}_{\text {fuel, } \mathrm{o}}=1$ indicates that no reaction of the fuel has taken place at a given time, $\tau_{\mathrm{R}}$. Also shown on the secondary y-axes of Fig. 6 are the temperatures (related to PFR mixture fraction via Eqs. 2 and 4) for each simulation. As expected, Fig. 6 shows that for low temperatures, no fuel reaction is observed for residence times up to $100 \mathrm{~ms}$ and that with increasing temperature (decreasing $\xi$ ), the time required for fuel reaction $\left(\mathrm{X}_{\text {fuel }} / \mathrm{X}_{\text {fuel,o }}<1\right)$ decreases rapidly. Because of the differences in the low-to-moderate temperature chemistry of $\mathrm{CH}_{4}, \mathrm{C}_{3} \mathrm{H}_{8}$, and DME, it is noted that the temperature/residence time coupling corresponding to the onset of fuel reaction is fuel dependent. In addition, the region in $\xi-\tau_{R}$ space corresponding to $0<X_{\text {fuel }} / X_{\text {fuel,o }}<1$ is fuel dependent with an abrupt consumption of fuel only at higher temperatures for $\mathrm{CH}_{4}$ with broader consumption regions originating at lower temperatures for $\mathrm{C}_{3} \mathrm{H}_{8}$ and DME, respectively.

The utility of the PFR simulations is exhibited when comparing to expected fluid mechanic/mixing time scales associated with the transient jet issuing into the hot co-flow. A characteristic convective time scale for any given mixture fraction, $\xi$, is estimated as

$$
\tau_{f}=\frac{\left(x-x_{p}\right)}{\left(U_{f}-U_{o x}\right) \xi+U_{o x}}
$$

where $x$ is the axial position, $x_{p}$ is the length of the jet potential core, $U_{f}$ is the velocity of the fuel jet exiting the nozzle, and $U_{o x}$ is the velocity of the hot co-flow. In Eq. (6), self-similarity between $\xi$ and ( $U$ -

\footnotetext{
${ }^{2}$ Perfectly-stirred reactor (PSR) simulations also were performed yielding nearly identical results as shown in Fig. 6.
} 
$\left.U_{o x}\right) /\left(U_{f}-U_{o x}\right)$ is assumed, where $U$ would represent the local axial velocity at a radial position corresponding to a mixture fraction $\xi$. For each operating condition, the potential core length, $x_{p}$, is estimated from turbulent jet mixing scaling relations [e.g., 45]. Shown in Fig. 6 are the calculated results for $\tau_{\mathrm{f}}$ at an axial position $\mathrm{x} / \mathrm{d}=20$ ( $\mathrm{d}$ is the nozzle diameter), which corresponds to the axial position of the formation of the initial auto-ignition kernels as discussed below. It is noted that based on the PFR simulations, no fuel reaction is expected for $\xi>\xi_{\mathrm{s}}$ for all fuels and operating conditions and for $\mathrm{CH}_{4}$ and $\mathrm{C}_{3} \mathrm{H}_{8}$, no fuel conversion is expected for all mixture fraction values greater than the experimental resolution $(\xi>0.02)$. Furthermore, the calculated $\tau_{\mathrm{f}}$ is a maximum possible residence time which assumes that any fluid parcel exiting the potential core is instantaneously increased to a temperature corresponding to $\mathrm{T}=\mathrm{T}(\xi)$ at $\mathrm{x} / \mathrm{d}=20$. In reality, any fluid parcel will experience a time variation in temperature as it mixes and advects downstream, thus significantly decreasing its residence time under higher-temperature (and reactive) conditions. This would appear as an effective "shift" of the $\tau_{\mathrm{f}}$ isolines to lower values for a given temperature. Thus, we expect that under the time scales of interest, the effects of fuel reaction are negligible for all experimental cases considered. The experimental results discussed in Sec. 4.2 confirm this assertion.

\subsection{Temperature Measurements after Ignition (Identifying Burning vs. Non-Burning Regions)}

As discussed in Sec. 3.3, the coupled relationship between $X_{\mathrm{f}}$ and $\mathrm{T}$ as described in Eqs. (3) and (4) is strictly valid only under mixing conditions prior to ignition. When combustion occurs locally, there will be a substantial temperature rise (and species formation with reduced $\sigma_{\text {mix }}$ ) such that the measured $\mathrm{S}_{\mathrm{RAY}} / \mathrm{S}_{\text {air }}$ is reduced below what would be expected for pure oxidizer at $\mathrm{T}=\mathrm{T}_{\mathrm{ox}}$. Consider the relationship between $S_{\mathrm{RAY}} / \mathrm{S}_{\mathrm{air}}$ and the local normalized mixture fraction, $\xi / \xi_{\mathrm{s}}$ as shown in Fig. 7. The solid lines represent the two-stream mixing cases described in Sec. 3.4 and the dashed lines represent the $\mathrm{S}_{\mathrm{RAY}} / \mathrm{S}_{\text {air }}$ which would result from complete combustion of the fuel and vitiated oxidizer stream for a given $\xi / \xi_{s}$. It 
is noted that for the cases with combustion, $S_{\mathrm{RAY}} / \mathrm{S}_{\text {air }}$ at any mixture fraction will be less than the minimum $S_{\mathrm{RAY}} / \mathrm{S}_{\text {air }}$ (pure oxidizer) for the mixing only cases. In this manner, the iterative procedure described in Sec. 3.3 would yield a negative fuel mole fraction value, $\mathrm{X}_{\mathrm{f}}<0$, for any isolated region with combustion (i.e., ignition kernel formation). While this is completely un-physical, it does serve as a "flag" in the data processing that the $X_{f}$ and T values computed via Eqs. (3) and (4) are no longer valid. Since $S_{\text {RAY }} / S_{\text {air }}$ is single valued, it is straight-forward to determine when combustion occurs locally.

Temperatures in the regions of the local ignition kernel (i.e., "burning") can be estimated with a sufficient level of accuracy (in terms of identifying reacted vs. un-reacted gas) even though accurate mixture fraction values may be difficult to recover. When the measured Rayleigh scattering signal ratio, $\mathrm{S}_{\mathrm{RAY}} / \mathrm{S}_{\text {air }}$, is less than $\mathrm{S}_{\mathrm{RAY}} / \mathrm{S}_{\mathrm{air}} \mid \mathrm{T}=\mathrm{T}_{\mathrm{ox}}$ and the data processing described by Eqs. (3) and (4) yields $\mathrm{X}_{\mathrm{f}}<0$, the methodology described in Sec. 3.3 is locally abandoned and the temperature is determined as $\mathrm{T}_{\mathrm{kr}}=$ $\mathrm{T}_{\text {air }} *\left(\mathrm{~S}_{\mathrm{RAY}} / \mathrm{S}_{\mathrm{air}}\right)^{-1}$, which is the equivalent as assuming that the local mixture-averaged Rayleigh scattering cross section (of the newly-formed combustion products) is equivalent to that of air. Since the ignition occurs under "lean" conditions (see Sec. 4.3), this approximation may be sufficient. To assess the accuracy of the temperature measurements in the region of the ignition kernel, Fig. 8 shows the estimated error as a function of mixture fraction, normalized by the stoichiometric value $\left(\xi / \xi_{\mathrm{s}}\right)$ with the implicit assumption that $\sigma_{\text {mix }}=\sigma_{\text {air }}$ in the kernel region. The "actual" species composition for a given mixture fraction is determined assuming a one-step reaction between the fuel and vitiated oxidizer combinations listed in Table 1 such that the local composition consists of $\mathrm{CO}_{2}, \mathrm{H}_{2} \mathrm{O}, \mathrm{N}_{2}$, and $\mathrm{O}_{2}$. The mixture-averaged Rayleigh scattering cross section is then computed as $\sigma_{\text {mix }}=\mathrm{X}_{\mathrm{CO} 2} \sigma_{\mathrm{CO} 2}+\mathrm{X}_{\mathrm{H} 2 \mathrm{O}} \sigma_{\mathrm{H} 2 \mathrm{O}}+\mathrm{X}_{\mathrm{N} 2} \sigma_{\mathrm{N} 2}+\mathrm{X}_{\mathrm{O} 2} \sigma_{\mathrm{O} 2}$ and an expected $S_{\mathrm{RAY}} / \mathrm{S}_{\text {air }}$ is calculated according to Eq. (1) for a temperature T. This signal ratio is taken as that which would be measured in the ignition kernel region. The temperature error, assuming $\sigma_{\text {mix }}=\sigma_{\text {air }}$ in the kernel region, is calculated as $\left(\mathrm{T}_{\mathrm{kr}}-\mathrm{T}\right) / \mathrm{T}$. As shown in Fig. 8, for lean conditions $\left(\xi<\xi_{\mathrm{s}}\right)$, the error from the aforementioned assumption is bound between $-6 \%$ and $3 \%$, with an increasing under-estimation of the temperature for increasing mixture fraction values. However, this uncertainty is well within 
acceptable limits for discerning the high-temperature regions associated with the burning region from the unreacted fuel/oxidizer mixture. It is emphasized that the method described in this section is applied locally only when ignition occurs and the processing methodology described under Sec. 3.3 yields $\mathrm{X}_{\mathrm{f}}<0$. In all other regions, the methodology presented in Sec. 3.3 is valid and used to produce the results discussed in Sec. 4.

\subsection{Planar Rayleigh Scattering Data Processing}

Proper reduction of the acquired Rayleigh signal is critical for quantitative measurements of $\xi$ and T. First, a background subtraction is required which eliminates the contribution of the camera "darkfield" noise and any ambient stray light. Similar to the procedure described in [27], the background image is determined by "padding" each image sequence with 40 images beyond the number of pulses within a burst. With no laser pulses present, the acquired images at the end of the image sequence represent an accurate representation of background contribution and the mean of these 40 images are subtracted from each individual image frame.

The second data reduction step is the correction for sensor non-uniformity, i.e., "whitefield" corrections. As described in [27], the CMOS sensors used in the present study demonstrate non-uniform sensor gain under short-duration (order ns) acquisition events. The non-uniformity is corrected by normalizing any instantaneous Rayleigh scattering measurement by a uniform reference condition. In part, this prompted the formulation of Eq. (3) to deduce $X_{f}$, in which the collected Rayleigh scattering signal $S_{\text {RAY }}$ is directly normalized by $S_{\text {air }}$, which implicitly corrects for sensor non-uniformity. The air calibration image was formulated by taking the mean of ten 100-image pulse bursts acquired while only the co-flowing air stream was operational. This process was repeated for each spatial location.

The third data reduction step involves corrections for non-uniformities in the laser-sheet intensity distribution, which also accounts for shot-to-shot laser energy fluctuations. As described in Sec. 2.2, a second "Sheet Correction Camera" simultaneously acquires planar Rayleigh scattering from a second 
uniform air stream. Any variations in the acquired signal are due to variations in the laser-sheet intensity distribution only and can be used to correct the same laser-sheet intensity fluctuations in the acquired images from the DLR JHC. Extensive care is taken to match the magnification, spatial offsets, and small angular differences between the two cameras. Once the geometry is matched, the average intensity distribution from a 15-pixel-wide column from the "Sheet Correction Camera" is used as the intensity distribution correction on the Rayleigh camera imaging the DLR JHC.

The fourth data processing procedure involves the implementation of the new methodology described in Sec. 3.3 and the final data reduction procedure involves the application of a $3 \times 3$ median filter to increase the signal-to-noise ratio. The use of the $3 \times 3$ median filter results in an effective inplane spatial resolution of $\sim 100 \mu \mathrm{m}$ [27], which is less than the out-of-plane spatial resolution defined by the laser sheet thickness $(280 \mu \mathrm{m})$. Based on measurements in a series of bar patterns with varying spatial frequencies, we estimate that the current in-plane spatial resolution allows mixture fraction gradients as high as $4 \mathrm{~mm}^{-1}$ to be measured accurately. The effect of the out-of-plane spatial resolution on the resolvable gradients has not been determined. Measurement noise limits the minimum spatial gradients that can be measured accurately. Based on the results presented below in Sec. 4.1, mixture fraction gradients as low as $0.1 \mathrm{~mm}^{-1}$ are measured accurately in the hot co-flow with smaller mixture fraction gradients resolvable (due to higher signal-to-noise ratios) at higher mixture fraction values.

\section{Results and Discussion}

\subsection{Measurement Fidelity - Boundary Conditions and Measurement Signal-to-Noise}

A primary goal of the current experiment is to enable the investigation of auto-ignition dynamics in a facility with well-defined and reproducible boundary conditions with a specific focus on acquiring simultaneous mixture fraction and temperature sequences with high signal-to-noise ratios. Since the autoignition process is sensitive to temperature, a detailed investigation of the high-temperature oxidizer coflow conditions was carried out. Figure 9 shows the average measured oxidizer temperature (determined from 100 single shot images) at an axial position of $\mathrm{x} / \mathrm{d}=20$ and a radial position of $\mathrm{r} / \mathrm{d}=5$ for all five 
oxidizer cases considered in Table 1 . The solid line represents the adiabatic flame temperature $\left(\mathrm{T}_{\mathrm{ad}}\right)$ as a function of equivalence ratio and the dashed line corresponds to a temperature condition $5 \%$ below $\mathrm{T}_{\mathrm{ad}}$. For the five cases considered, measured co-flow temperatures are $3 \%$ to $6 \%$ below $\mathrm{T}_{\mathrm{ad}}$, where the average measured co-flow temperature is $4.6 \%$ below $\mathrm{T}_{\text {ad }}$, which is well-represented by the dashed line shown in Fig. 9. The measured oxidizer temperatures are consistent with small heat losses to the burner matrix in addition to uncertainties in the co-flow mass flow rates (equivalence ratios) and uncertainties in the Rayleigh scattering measurement.

Figure 10 shows three radial temperature profiles $(-20<\mathrm{r}(\mathrm{mm})<20)$ at an axial position of $\mathrm{x} / \mathrm{d}$ $=20$ corresponding to three different oxidizer conditions with co-flow temperatures ranging from $1270 \mathrm{~K}$ to $1490 \mathrm{~K}$ and no jet flow. The red lines correspond to radial profiles from instantaneous temperature images and the black lines represent the average radial temperature profile from 100 images. Both profiles correspond to one pixel in the vertical direction. The dashed line represents the adiabatic temperature and is shown for reference. Around $\mathrm{r} / \mathrm{d}=0$, there is a small temperature decrease due to heat loss to the fuel nozzle which is in contact with the water-cooled bronze matrix. The magnitude of the temperature drop increases slightly with increasing oxidizer temperature and ranges from $1.5 \%(19 \mathrm{~K})$ at a co-flow temperature of $1270 \mathrm{~K}$ to $3.2 \%(48 \mathrm{~K})$ at a co-flow temperature of $1490 \mathrm{~K}$. The radial extent of the temperature deficit is $-3<\mathrm{r} / \mathrm{d}<3$. Finally, it is noted that the instantaneous temperature profiles align very well with the mean temperature profiles indicating a high degree of reproducibility of the boundary conditions in the DLR JHC.

To examine the signal-to-noise ratio (SNR) of instantaneous temperature measurements (such as those presented in Fig. 10), probability density functions (pdfs) of the measured co-flow temperatures were determined from 15,000 data points from a single temperature image in a spatial region bounded by $17<\mathrm{x} / \mathrm{d}<23$ and $6<\mathrm{r} / \mathrm{d}<9$. The pdfs of the measured co-flow temperature for the same example cases shown in Fig. 9 are displayed in Fig. 11. The SNR is defined as the mean temperature divided by the standard deviation of the 15,000 data points. As shown in Fig. 11, the current measurements exhibit a low level of uncertainty due to measurement noise with SNRs of 108, 100, and 58 at average co-flow 
temperatures of $1270 \mathrm{~K}, 1330 \mathrm{~K}$, and $1490 \mathrm{~K}$, respectively. Figure 12 shows three individual time traces of temperature at single spatial position $(\mathrm{x} / \mathrm{d}=20$ and $\mathrm{r} / \mathrm{d}=7.5)$ for the same three operating conditions referenced in Figs. 10 and 11. The time traces are $10 \mathrm{~ms}$ long corresponding to 100 measurement points at a $10-\mathrm{kHz}$ acquisition rate. Similar to the trends exhibited in the instantaneous radial profiles and the spatial pdfs shown in Figs. 10 and 11, the SNR of the time-series measurement decreases with increasing co-flow temperature. However, it is noted that the SNR of the time-series measurements (at a single spatial position) are higher corresponding to SNR values of 195, 129, and 78 at average co-flow temperatures of $1270 \mathrm{~K}, 1330 \mathrm{~K}$, and $1490 \mathrm{~K}$, respectively. More specifically the reported SNR values imply that for the lowest pre-ignition signal levels (i.e., the hot oxidizer), the precision of the measurements due to measurement noise and facility repeatability is $6.5 \mathrm{~K}, 10.3 \mathrm{~K}$, and $19.1 \mathrm{~K}$ for the cases with $1270 \mathrm{~K}, 1330 \mathrm{~K}$, and $1490 \mathrm{~K}$ coflow temperatures, respectively, which is equivalent to precision in mixture fraction measurements of $0.003,0.004$, and 0.009 , respectively. It is noted that the precision of the temperature and mixture fraction results further increase with decreasing temperature (increasing mixture fraction). This demonstrates the high quality of the pulse trains from the HEPBLS over extended burst durations. The higher SNR values of the single-point, temperature time-series measurements as compared to the spatial measurements for a single instantaneous temperature image is attributed to the effect of the laser-sheet intensity correction in the axial direction as well as a small inhomogeneity of the oxidizer temperature field in the radial direction.

The results presented in Figs 9-12 demonstrate that the auto-ignition measurements (under turbulent fuel injection) discussed below are conducted with very high precision and occur under highly repeatable and nearly-isothermal boundary conditions. To put into the context the value of the high precision and facility repeatability, we consider PSR reactor cases representative of the case of DME fuel issuing into the $1330 \mathrm{~K}$ coflow. We examined the ignition of two cases: (1) $\xi=0.01(\mathrm{~T}=1310 \mathrm{~K})$ and (2) $\xi=0.014(\mathrm{~T}=1300 \mathrm{~K})$, where the difference in mixture fraction (temperature) values represents the uncertainty in the mixture fraction (temperature) measurement due to SNR and facility effects. Between 
the two cases, the ignition delay time changes by less than $0.08 \mathrm{~ms}$, which is less than the sampling resolution of the current $10-\mathrm{kHz}$ measurements $(0.1 \mathrm{~ms})$. In this manner, in the absence of turbulence or transport effects, the precision of the measurements is sufficient to capture the correct temperature/mixture fraction-ignition delay relationship within the temporal resolution limitation imposed by the $10-\mathrm{kHz}$ measurements. Furthermore, as will be discussed in Sec. 4.3, the ignition delay under turbulent fuel injection occurs between 1.7 and $4.2 \mathrm{~ms}$ for the current test cases, thus the precision of the current temperature and mixture fraction measurements is sufficient for investigating auto-ignition with turbulent fuel injection under the current operating conditions

\subsection{Self Similarity and Comparison to "Cold", Non-reacting Jets}

To assess the accuracy of the mixture fraction (and corresponding temperature) measurements and confirm the assertions presented in Sec. 3.4 that fuel reaction (prior to auto-ignition) is negligible under the current operating conditions, the mean mixture fraction profiles from the DLR JHC are compared to “cold", non-reacting turbulent jet results. Mixture fraction measurements were acquired in non-reacting propane jets issuing into a low-speed $(0.3 \mathrm{~m} / \mathrm{s})$ co-flowing air stream at Reynolds $(\mathrm{Re})$ numbers ranging from 10,000 to 30,000 . Both the fuel and the co-flowing air stream were at $300 \mathrm{~K}$. The optical and imaging systems were the same as used for the JHC measurements and the data analysis for the nonreacting jets was described in [27]. It is expected that the mean conserved scalar field of a non-reacting axisymmetric jet will collapse to single curve across all Reynolds number conditions and axial positions when properly normalized by an appropriate similarity variable. Figure 13 shows the results of two "cold" non-reacting turbulent jets at $\operatorname{Re}=10,000$ and 30,000 at an axial position of $x / d=20$. The mean profiles, shown as the 'dashed' lines, are constructed from 300 sets of 200 sequential images (i.e., 60,000 individual measurements) and have been normalized by the mean centerline value $\left(\xi_{\mathrm{cc}}\right)$ for each operating condition. The radial position has been normalized by the $r_{1 / 2}$ position, which is denoted as the location where the mean mixture fraction value is $50 \%$ of the mean centerline value. As expected, the two "cold", non-reacting jet curves collapse to a single curve. 
The solid curves in Fig. 13 represent mean mixture fraction profiles at $\mathrm{x} / \mathrm{d}=20$ for three of the JHC operating conditions described in Table 1 for $\mathrm{CH}_{4}, \mathrm{C}_{3} \mathrm{H}_{8}$, and DME fuels; the same conditions which have been the subject of results shown in Figs. 6 and 9-11. For each case, the mean mixture fraction profile is constructed from > 150 individual images at $1.9 \mathrm{~ms}, 2.2 \mathrm{~ms}$, and $2.2 \mathrm{~ms}$ after fuel injection for the methane, propane, and DME cases, respectively. This time was chosen to be long enough following fuel injection such that any transient effects had subsided, but short enough such that the measurement was taken prior to auto-ignition. Similar to the "cold" cases described above, the mean mixture fraction profiles have been normalized by the mean centerline value $\left(\xi_{\mathrm{cl}}\right)$ for each operating condition and the radial position has been normalized by the $r_{1 / 2}$ position. If any appreciable fuel reaction was occurring, then the local Rayleigh scattering cross-section would be reduced as the consumption of the parent fuel would produce smaller hydrocarbons and hydrogen-containing species with smaller scattering cross sections. In this manner, the local measured $\mathrm{S}_{\mathrm{RAY}} / \mathrm{S}_{\text {air }}$ would decrease, which would yield a lower $\mathrm{X}_{\mathrm{f}}(\mathrm{Eq}$. 3) and $\xi$, which would appear as a "dip" in the mixture fraction profiles as compared to the "cold" jet cases. As shown in Fig. 13, the mean mixture fraction profiles from the turbulent fuel jets issuing into high-temperature oxidizing co-flows collapse onto the "cold" jet cases, indicating accuracy of the data reduction methodology as described in Sec. 3.3 and no apparent fuel reaction chemistry as asserted in Sec. 3.4.

\subsection{Mixture Fraction and Temperature Evolution from Injection to Auto-Ignition}

Figure 14 shows a five-frame image sequence of the derived mixture fraction and temperature fields during transient fuel injection for the case of $\mathrm{C}_{3} \mathrm{H}_{8}$ issuing into a $\mathrm{T}=1270 \mathrm{~K}$ oxidizing co-flow. The high SNR of the measurements is apparent in the reported image sequence. The images are centered at an axial position of $\mathrm{x} / \mathrm{d}=20$ and span a radial distance of $-4<\mathrm{r} / \mathrm{d}<4$. The first image in the sequence corresponds to approximately $1.7 \mathrm{~ms}$ after triggering of the $2 / 2$ solenoid valve. By tracking the displacement of the leading edge of the jet tip as a function of frames 1-4, the impulsively-started jet 
velocity is approximately 40 to $50 \mathrm{~m} / \mathrm{s}$, which is somewhat lower than the steady-state exit velocity of 72 $\mathrm{m} / \mathrm{s}$ listed in Table 1 . This is most likely due to a local deceleration of the jet due to mass entrainment, which would occur at an axial position of $\mathrm{x} / \mathrm{d}=20$ during steady-state operation. However after the initial transient passes a given spatial region (frame 5), the jet starts to exhibit an appearance similar to that expected from steady-state jets. It is noted that even during this initial transient, the peripheral interface between the fuel and oxidizer is highly turbulent with a high degree of surface wrinkling and the apparent influence of vortical structures.

As discussed in Sec. 2.2, the $\mathrm{OH}^{*} \mathrm{CL}$ images are used to denote the onset of auto-ignition through the formation of the initial ignition kernel. The goal of the current experiment (and future analysis) is to understand the mixing and mixing rate conditions present at the onset of ignition. Since the Rayleigh scattering imaging is two-dimensional, all analysis should include only data sets in which the initial kernel formed within the probe volume defined by the laser sheet used for the planar Rayleigh scattering measurements. Figure 15 shows two example $\mathrm{OH}^{*} \mathrm{CL}$ image sequences at an axial position of $\mathrm{x} / \mathrm{d}=20$. The top row of each image sequence is from " $\mathrm{OH}^{*} \mathrm{CL}$ Camera 1" and the bottom row is from "OH* $\mathrm{CL}$ Camera 2" as shown in Fig. 3. Comparing the image sequences in Fig. 15(a) and (b) for the top row only, it is unknown where the initial ignition kernel formed with respect to the measurement plane of the mixture fraction and temperature fields. However, the utility of "OH* CL Camera 2" is demonstrated by examining the bottom image sequences in Fig. 15 (a) and (b). The vertical "dashed" line represents the location (and approximate thickness) of the 532-nm laser sheet used for the planar Rayleigh scattering measurements. In Fig. 15a, the ignition kernel, inferred from the $\mathrm{OH}^{*}$ images, occurs within the laser probe volume, while in Fig. 15b, the initial $\mathrm{OH}^{*}$ signature forms outside of the laser sheet.

Only mixture fraction and temperature image sequences in which the $\mathrm{OH}^{*} \mathrm{CL}$ is detected within the laser sheet volume (similar to Fig. 15a) are used within all subsequent analysis. The processing details are described in [14] and briefly include first thresholding the background-corrected OH* CL images, followed by the calculation of the centroid of the first detected kernel. If the centroid of the kernel was within $\pm 0.75 \mathrm{~mm}$ of the center of the laser sheet, the kernel was considered to have formed within the 
laser sheet. The minimum size for detecting a kernel was set to $1 \mathrm{~mm}^{2}$ in the processing (in order to suppress noise from the image intensifier); however, the majority of the detected kernels were larger than $4 \mathrm{~mm}^{2}$, so that the majority of the kernel was within the laser light sheet. Finally, the image sequences of Fig. 15a can be used to estimate two-dimensional (Rayleigh) measurement effects in terms of quantifying the conditions occurring at the onset of ignition. From Fig. 15a it is noted that if the ignition kernel $\left(\mathrm{OH}^{*}\right.$ CL) initially forms inside of the laser sheet volume, out-of-plane movement effects are negligible for the timescales of interest in the current experiment.

Figures 16 and 17 show example image sequences of the mixture fraction (top), $\mathrm{OH}^{*} \mathrm{CL}$ (middle), and temperature (bottom) fields prior to and at the onset of auto-ignition for turbulent fuel injection into a hot, vitiated co-flow. Figure 16 represents the case of $\mathrm{C}_{3} \mathrm{H}_{8}$ injection at $\mathrm{Re}=34,100$ into a $1270 \mathrm{~K}$ coflow and Fig. 17 represents the case of $\mathrm{CH}_{4}$ injection at $\mathrm{Re}=12,000$ into a $1490 \mathrm{~K}$ co-flow. Both image sequences are centered at an axial position of $\mathrm{x} / \mathrm{d}=20$ and were acquired at $10 \mathrm{kHz}(100 \mu$ s separation). The five sequential images are only a subset of the full 100-image sequence. The mixture fraction and temperature images have been placed on quantitative scales using Eqs. (2) - (4) and the variations in mixture fraction and temperature are represented with a false color map to highlight the high scalar gradients through the flowfield. The mixture fraction images (top row) are shown with a logarithmic scale due to the large dynamic range of the measurements. In both Figs. 16 and 17, the spatial location corresponding to the occurrence of the initial ignition kernel is denoted with a white circle on all three image sequences. The ignition kernel is denoted as the location in which the observed $\mathrm{OH}^{*}$ signature is > $10 \%$ above the background signal level. It is noted in Figs. 16 and 17 that the circled regions of the mixture fraction and temperature images are offset from the $\mathrm{OH}^{*} \mathrm{CL}$ images. This is an artifact of the alignment of the $\mathrm{OH}^{*}$ CL Camera 1 (see Fig. 3) which is offset 15 degrees to the Rayleigh scattering camera. However, the two circled regions correspond to the same location in physical space.

The occurrence of the ignition kernel in Fig. 16 for the case of $\mathrm{C}_{3} \mathrm{H}_{8}$ issuing into the $1270 \mathrm{~K}$ oxidizer is $4.5 \mathrm{~ms}$ following triggering of the $2 / 2$ solenoid valve, which corresponds to $4.2 \mathrm{~ms}$ following fuel injection from the nozzle, and $2.7 \mathrm{~ms}$ after the transient fuel jet first reaches an axial position of $\mathrm{x} / \mathrm{d}=$ 
20. Similarly, the occurrence of the ignition kernel in Fig. 17 for the case of $\mathrm{CH}_{4}$ issuing into the $1490 \mathrm{~K}$ oxidizer is $2 \mathrm{~ms}$ following triggering of the $2 / 2$ solenoid valve, which corresponds to $1.7 \mathrm{~ms}$ following fuel injection from the nozzle, and $1.3 \mathrm{~ms}$ after the transient fuel jet first reaches an axial position of $\mathrm{x} / \mathrm{d}=$ 20. First, it is noted that the ignition delay time is short compared to the full 10 -ms image sequences such that the full auto-ignition process is captured for each acquired image sequence. Second, it is noted that the formation of the initial ignition kernel occurs at the periphery of the jet at what appears to be very "lean" mixtures $\left(\xi<\xi_{\mathrm{s}}\right)$. This is consistent with previous DNS work that has shown that the "fastest" auto-ignition time occurs for the most reactive mixture fraction, $\xi_{\mathrm{MR}}$ as discussed in Sec. 1, which for the case of cold fuel issuing into a hot oxidizer stream, $\xi_{\mathrm{MR}}<\xi_{\mathrm{s}}$.

Figure 18 shows an example ten-image sequence of $\mathrm{OH}^{*} \mathrm{CL}$ and temperature for the $\mathrm{Re}=38,480$ case of DME issuing into a $\mathrm{T}=1330 \mathrm{~K}$ oxidizer stream. This DME case is highlighted as it has the highest stoichiometric mixture fraction of the pure fuel cases considered and regions of $\xi / \xi_{\mathrm{s}}$ as low as 0.15 are resolved with the current system and the corresponding measurement SNR. It is observed in the Fig. 18 image sequences that the $\mathrm{OH}^{*}$ kernel formation and its initial evolution is highly correlated with a temperature rise above the oxidizer temperature, $\mathrm{T}_{\mathrm{ox}}$, which is expected. As noted in Sec. 3.5, the temperature in the region of the ignition kernel can be estimated with sufficient accuracy and thus the onset of ignition can be determined directly from the deduced temperature fields. This is somewhat advantageous as the Rayleigh scattering images have significantly higher SNR as compared to the $\mathrm{OH}^{*}$ $\mathrm{CL}$ images and as the ignition kernel evolves the line-of-sight nature of the $\mathrm{OH}^{*} \mathrm{CL}$ images may lead to some difficulty in interpretation. In this manner, the mixture fraction and temperature images (deduced from high-speed planar Rayleigh scattering) are used to examine the relationship between the mixing/temperature topology, local mixing rates, and the onset of auto-ignition.

Similar to the results shown in Figs. 16 and 17, the initial auto-ignition event in Fig. 18 occurs at the periphery of the jet in a highly cusped region and continues to evolve along the periphery as well. The occurrence of the initial ignition kernel along the periphery of the jet and within a cusped region is 
consistent with previous DNS results [e.g., 15,19, 20-22,24,25] which suggest that ignition will occur in regions of low strain and scalar dissipation rate, possibly coinciding with the cores of vortices. In addition, it is noted that the time between the arrival of the tip of the fuel jet to ignition $(\sim 1.8 \mathrm{~ms}$ for the DME sequence shown in Fig. 18) is long as compared to the ignition delay time for the case of a homogenous reactor simulation $(<0.9 \mathrm{~ms})$ indicating the effects of transport processes and more importantly, strain and scalar dissipation rate on the ignition process [e.g., 1, 14]. Figure 19 shows a sequence of scalar dissipation rate images corresponding to frames 2- 6 of Fig. 18. In this work, the scalar dissipation rate is defined as $\chi=\nabla \xi \bullet \nabla \xi$ and describes the rate of mixing of a system. It is noted that this definition of the scalar dissipation rate is simply proportional to the conventional definition which includes the effect of diffusivity. Neglecting diffusivity does not impact any of the subsequent conclusions. The natural logarithm of the scalar dissipation rate, $\ln (\chi)$, is shown in Fig. 19 to highlight the regions of the scalar mixing gradients. The ability to calculate $\chi$ (a squared gradient quantity) without additional image filtering demonstrates the quality of the mixture fraction measurements. Overlaid on the scalar dissipation rate fields is the stoichiometric mixture fraction contour $\left(\xi=\xi_{\mathrm{s}}\right)$ denoted as the solid blue line and iso-contours of the temperature field corresponding to a $50 \mathrm{~K}$ increase above $\mathrm{T}_{\mathrm{ox}}$ denoted as the solid red lines, which is used to indicated the onset of ignition. The image sequences in Fig. 19 confirm that for the cases considered in the present study, auto-ignition occurs under lean mixture fraction conditions and in regions experiencing low scalar dissipation rate. Time traces of mixture fraction, temperature, and scalar dissipation rate (not shown here) show that flammable mixtures are present in the kernel formation region sufficiently prior to ignition; however, the combination of mixture flammability, high temperature, and low scalar dissipation rate are necessary to support the initial ignition event.

\section{Summary, Conclusions, and Future Work}

In this manuscript, we have described an experimental methodology to simultaneously measure highspeed image sequences of the mixture fraction, temperature, and $\mathrm{OH}^{*}$ emission fields during transient 
fuel injection into a high-temperature, co-flowing, vitiated, oxidizer stream. The quantitative mixture fraction and temperature fields are determined from $10-\mathrm{kHz}$-rate planar Rayleigh scattering and the $\mathrm{OH}^{*}$ emission is used to determine the formation of the initial ignition kernel which denotes the onset of autoignition. High-speed planar Rayleigh scattering imaging is enabled by the unique high-energy pulse burst laser system (HEPBLS) [26, 27], which produces long-duration (up to $25 \mathrm{~ms}$ ) bursts of ultra-high-energy output at $532 \mathrm{~nm}$. In this study, pulse energies exceeding 1 Joule were used for the planar Rayleigh scattering imaging. The high-speed laser and optical measurements were performed in the wellcharacterized DLR JHC facility [12-14] using various "cold" fuel and "hot" oxidizer combinations.

We established a robust data processing methodology for accurately determining the coupled mixture fraction and temperature fields from a single planar Rayleigh scattering measurement in conjunction with enthalpy conservation that is valid from fuel injection through the onset of ignition. Furthermore, we established a methodology for deducing temperature following ignition with sufficient accuracy to identify "burning" regions and the initial evolution of the ignition kernel following formation. A particular focus of this study was to characterize the fidelity of the measurements in the context of the repeatability of the DLR JHC facility operating and boundary conditions and the accuracy and precision of the high-speed measurements. The boundary conditions of the DLR JHC were found to be highly stable and reproducible in terms of oxidizer temperature and pulsed fuel injection. The temperature fields deduced from the planar Rayleigh scattering measurements exhibited extremely high signal-to-noise ratios exceeding 100 in $\mathrm{T} \sim 1300 \mathrm{~K}$ co-flows. The accuracy of the mixture fraction measurements were determined by comparing normalized radial profiles to isothermal $(\mathrm{T}=300 \mathrm{~K})$, non-reacting jets. All profiles, when properly normalized, exhibited self-similarity and collapsed upon one another indicating that (i) no detectable fuel reaction was occurring in the present measurements of cold fuel injection into high-temperature oxidizer streams and (ii) the data processing methodology yielded accurate high-speed mixture fraction (and subsequently temperature) measurements in the auto-igniting environment.

Example mixture fraction, temperature, and $\mathrm{OH}^{*}$ emission image sequences for $\mathrm{CH}_{4}, \mathrm{C}_{3} \mathrm{H}_{8}$, and dimethyl ether (DME) fuels issuing into vitiated co-flows with temperatures varying from $1270 \mathrm{~K}$ to 1490 
K were presented highlighting new aspects of auto-ignition dynamics. Particular focus was placed on the relative roles of mixing and mixing rates on the onset of auto-ignition. Sample results showed that the turbulent ignition delay times for all fuel/oxidizer combinations were much greater than that which would occur under laminar, homogeneous reactor conditions, indicating the influence of transport and strain and scalar dissipation rates imposed by the turbulent flow and mixing processes. For all cases considered, auto-ignition occurred at the periphery of the fuel jet, under very "lean" conditions, where the local mixture fraction was less than the stoichiometric mixture fraction $\left(\xi<\xi_{s}\right)$. Furthermore, the ignition kernel formed in regions of low scalar dissipation rate, which agrees with previous numerical results [e.g., $15,19,20-22,24,25]$.

Future work will include the investigation of auto-ignition dynamics using diluted fuels such that the stoichiometric mixture fraction is increased as compared to the current cases using pure fuels. In this manner, the resolvable $\xi / \xi_{\mathrm{s}}$ is greatly reduced for the same system resolution limits, allowing quantification of the local mixing conditions necessary to support auto-ignition and an accurate determination of the most reactive mixture fraction, $\xi_{\mathrm{MR}}$. In addition, higher acquisition rates beyond 10 $\mathrm{kHz}$ will be used to better resolve the dynamics of auto-ignition under high-speed fuel injection. The coupling of the planar Rayleigh scattering with additional species measurements such as $\mathrm{OH}$ and $\mathrm{CH}_{2} \mathrm{O}$ may be advantageous, where the latter quantity can give insight into the role of lower-temperature chemistry and partial-oxidation products on the auto-ignition process.

\section{Acknowledgments}

Financial support within the DLR projects IVTAS and PIZ-0182-737 is gratefully acknowledged. Work at Ohio State was supported by the Combustion Energy Frontier Research Center, funded by DOE, Office of Science, Basic Energy Sciences under Award DE-SC0001198. The authors wish to thank Campbell Carter and Tonghun Lee for the use of high-speed imaging equipment. 


\section{References}

1. Mastorakos, E., Ignition of Turbulent Non-Premixed Flames, Prog. Energy and Comb. Sci. 2009, 35, 5797.

2. Boxx, I. Stöhr, M., Carter, C.D., Meier, W., Laser-Based Investigations in Gas Turbine Model Combustors, Exp. Fluids, 2010, 49, 865-882.

3. Markides, C.N., Mastorakos, E., An Experimental Study of Hydrogen Autoignition in a Turbulent Co-Flow of Heated Air, Proc. Combust. Inst., 2005, 30, 883-891.

4. Markides, C.N., Mastorakos, E., Experimental Investigation of the Effects of Turbulence and Mixing on Autoignition Chemistry, Flow, Turb. and Combust., 2011, 86, 585-608.

5. Cabra, R., Myhrvold, T., Chen, J.Y., Dibble, R.W., Karpetis, A.N., Barlow, R.S., Simultaneous Laser Raman-Rayleigh-LIF Measurements and Numerical Modeling Results of a Lifted Turbulent H2/N2 Jet Flame in a Vitiated Flow, Proc. Combust. Inst. 2002, 29, 1881-1888.

6. Cabra, R., Chen, J.Y., Dibble, R.W., Karpetis, A.N., Barlow, R.S., Lifted Methane-Air Jet Flames in a Vitiated Coflow, Combust. Flame 2005, 143, 491-506.

7. Gordon, R.L., Masri, A.R., Mastorakos, E., Simultaneous Rayleigh Temperature, OH- and CH2OLIF Imaging of Methane Jets in a Vitiated Co-Flow, Combust. Flame 2008, 155, 181-195.

8. Gordon, R.L., Masri, A.R., Mastorakos, E., Heat Release Rate as Represented by [OH] x [CH2O] and its Role in Autoignition, Combust. Theory, Model. 2009, 13, 645-670.

9. Sadanandan, R., Markus, D., Schieß1, R., Maas, U., Olofsson, J., Seyfried, H., Richter, M., Aldén, M., Detailed Investigation of Ignition by Hot Gas Jets, Proc. Combust. Inst. 2007, 31, 719-726.

10. Fast, G., Kuhn, D., Class, A.G., Maas, U., Autoignition During Instationary Jet Evolution of Dimethyl Ether (DME) in a High-Pressure Environment, Combust. Flame 2009, 156, 200-213.

11. Oldenhof, E., Tummers, M.J., van Veen, E.H.., Roakaerts, D.J.E.M., Transient Response of the Delft Jet-in-Hot Coflow Flames, Combust. Flame 2012, 159, 697-706.

12. Meier, W., Boxx, I., Arndt, C., Gamba, M., Clemens, N., Investigation of Auto-Ignition of Pulsed Methane Jet in Vitiated Air Using High-Speed Imaging Techniques, J. Eng. Gas Turb. Power 2011, 29, 021504-1-021504-6

13. Arndt, C.M., Schieß1, R., Gounder, J.D., Meier, W., Aigner, W., Flame Stabilization and AutoIgnition of Pulsed Methane Jets in a Hot Coflow: Influence of Temperature, Proc. Combust. Inst. 2013, 34, 1483-1490

14. Arndt, C.M., Gounder, J.D., Meier, W., Aigner, M., Auto-Ignition and Flame Stabilization of Pulsed Methane Jets in a Hot Vitiated Coflow Studied with High-Speed Laser and Imaging Techniques, Appl. Phys. B, 2012, 108, 407-417.

15. Sreedhara S., Lakshimisha, K.N., Direct Numerical Simulation of Autoignition in a Non-Premixed Turbulent Medium, Proc. Combust. Inst. 2000, 28, 1619-1627.

16. Cao, S., Echekki, T., Autoignition in Nonhomogenous Mixtures: Conditional Statistics and Implications for Modeling, Combust. Flame 2007, 151, 120-141.

17. Viggiano, A., Magi, V., A 2-D Investigation of n-Heptane Autoignition by Means of Direct Numerical Simulation, Combust. Flame 2004, 137, 432-443.

18. Sreedhara, S., Lakshmisha, K.N., Autoignition in a Non-Premixed Medium: DNS Studies of the Effects of Three-Dimensional Turbulence, Proc. Combust. Inst. 2002, 29, 2051-2059. 
19. Doom, J., Mahesh, K., Direction Numerical Simulation of Auto-Ignition of a Hydrogen Vortex Ring Reacting with Hot Air, Combust. Flame 2009, 156(4). 813-825.

20. Hilbert, R., Thevenin, D., Autoignition of Turbulent Non-Premixed Flames Investigated Using Direct Numerical Simulations, Combust. Flame 2002, 128, 22-44.

21. Im, H.G., Chen, J.H., Law, C.K., Ignition of Hydrogen-Air Mixing layer in Turbulent Flows, Proc. Combust. Inst. 1998, 27, 1047-1056.

22. Echekki, T., Chen, J.H., Direct Numerical Simulation of Autoignition in Nonhomogeneous Hydrogen-Air Mixtures, Combust. Flame 2003, 134, 169-191.

23. Mastorakos, E., Baritaud, T.A., Poinsot, T.J., Numerical Simulation of Autoignition in Turbulent Mixing Flows, Combust. Flame, 1997, 109, 198-223.

24. Hasegawa, T., Arai, A., Kadowaki, S., Yamaguchi, S., Autoignition of a Turbulent Premixed Gas, Combust. Sci. Tech. 1992, 84, 1-13.

25. Mastorakos, E., Pires Da Cruz, A., Baritaud, T.A., Poinsot, T.J., A Model for the Effects of Mixing on the Autoignition of Turbulent Flows, Combust. Sci. Tech. 1997, 125, 243-282.

26. Fuest, F., Papageorge, M.J., Lempert, W.R., Sutton, J.A., Ultra-High Laser Pulse Energy and Power Generation at $10 \mathrm{kHz}$, Opt. Lett., 2012, 37(15), 3131-3133.

27. Papageorge, M.J., McManus, T.A., Fuest, F., Sutton, J.A., Recent Advances in High-Speed Planar Rayleigh Scattering in Turbulent Jets and Flames: Increased Record Lengths, Acquisition Rates, and Image Quality, Appl. Phys. B., 2014, 115, 197-213.

28. Patton, R.A., Gabet, K.N., Jiang, N., Lempert, W.R., Sutton, J.A., Multi-kHz Mixture Fraction Imaging in Turbulent Jets Using Planar Rayleigh Scattering, Appl. Phys. B, 2011, 106(2), 457-471.

29. Patton, R.A., Gabet, K.N., Jiang, N., Lempert, W.R., Sutton, J.A., Multi-kHz Temperature Imaging in Turbulent Nonpremixed Flames Using Planar Rayleigh Scattering, Appl. Phys.B, 2012 108(2), 377-392.

30. Gabet, K.N., Jiang, N., Lempert, W.R., Sutton, J.A., Demonstration of High-Speed 1D Raman Scattering Line Imaging, Appl. Phys. B, 101 (1-2) (2010) 1-5.

31. Jiang, N., Patton, R.A., Lempert, W.R., Sutton, J.A., Development of High-Repetition Rate CH PLIF Imaging in Turbulent Nonpremixed Flames, Proc. Combust. Inst. 2010, 31(1), 767-774.

32. Gabet, K.N., Patton, R.A., Jiang, N., Lempert, W.R., Sutton, J.A., High-Speed $\mathrm{CH}_{2} \mathrm{O}$ PLIF Imaging in Turbulent Flames Using a Pulse Burst Laser System, Appl. Phys. B, 2012 106(3), 569-575.

33. Hunt, J.T., Glaze, J.A., Simmons, W.W., Renard, P.A., Suppression of Self-Focusing through LowPass Filtering and Relay Imaging, App. Opt., 1978, 17(13), 2053-2057.

34. Jiang, N., Lempert, W.R., Switzer, G.L., Meyer, T.R., Gord, J.R., Narrow-Linewidth MegahertzRepetition-Rate Optical Parametric Oscillator for High-Speed Flow and Combustion Diagnostics, Applied Optics 2008 47(1), 64-71.

35. Prucker, S. Meier, W., Stricker, A Flat Flame Burner as Calibration Source for Combustion Research - Temperatures and Species Concentrations of Premixed H2/Air Flames, W., Rev. Sci. Instrum., 1994, 65(9), 2908-2911.

36. Joshi, A., Schreiber, W., An Experimental Examination of an Impulsively Started Incompressible Turbulent Jet, Exp. Fluids, 2006, 40(1), 156-160. 
37. Meier, W., Barlow, R.S., Chen, Y.L., Chen, J.Y., Raman/Rayleigh/LIF Measurements in a Turbulent $\mathrm{CH}_{4} / \mathrm{H}_{2} / \mathrm{N}_{2}$ Jet Diffusion Flame: Experimental Techniques and Turbulence-Chemistry Interaction, Combustion and Flame 2000, 123(3), 326.

38. Bergmann, V., Meier, W., Wolff, D., Stricker, W., Application of Spontaneous Raman and Rayleigh Scattering and 2D LIF for the Characterization of a Turbulent CH4/H2/N2 Jet Diffusion Flame, Applied Physics B-Lasers and Optics 1998, 66(4), 489.

39. Gregor, M.A, Dreizler, A., A Quasi-Adiabatic Laminar Flat Flame Burner for High Temperature Calibration, Measurement Science and Technology 2009, 20(6), 065402.

40. Gordon, S., McBride, B.J., Computer Program for Calculation of Complex Chemical Equilibrium Compositions and Applications- I. Analysis, NASA Reference Publication 1311 (1994).

41. Espey, C., Dec, J.E., Litzinger, T.A., Satavicca, D.A., Planar Laser Rayleigh Scattering for Quantitative Vapor-Fuel Imaging in a Diesel Jet, 1997, Combust. Flame, 109, 65-86.

42. Smith, G.P., Golden, D.M., Frenklach, M., Moriarty, N.W., Eiteneer, B., Goldenberg, M., Bowman, C.T., Hanson, R.K., Song, S., Gardiner, Jr., W.C., Lissianski, V.V., Qin, Z. http://www.me.berkeley.edu/gri_mech/

43. Wang, H., You, H., Joshi, A.V., Davis, S.G., Laskin, A., Egolfopoulos F., Law, C.K., USC Mech Version II. High-Temperature Combustion Reaction Model of H2/CO/C1-C4 Compounds. http://ignis.usc.edu/USC_Mech_II.htm, May 2007.

44. Zhao, Z., Chaos, M., Kazakov, A., Dryer, F.L., Thermal Decomposition Reaction and a Comprehensive Kinetic Model of Dimethyl Ether, Int. J. Chem. Kin. 2008, 40, 1-18.

45. Tacina, K.M., Dahm, W.J.A., Effects of Heat Release on Turbulent Shear Flows. Part 1. A General Equivalence Principle for Non-Buoyant Flows and its Application to Turbulent Jet Flames, 2000, Journal of Fluid Mechanics, 415, 23-44. 
Table 1 - Operating Conditions

\begin{tabular}{cccc|ccccccc}
\hline \multicolumn{3}{c}{ Jet } & & \multicolumn{7}{c}{ Co-Flow } \\
\hline Fuel & $\mathbf{U}(\mathbf{m} / \mathbf{s})$ & $\mathbf{R e}$ & $\boldsymbol{\xi}_{\mathbf{s}}$ & $\boldsymbol{\phi}$ & $\dot{\mathbf{m}}(\mathbf{k g} / \mathbf{s})$ & $\mathbf{T}_{\mathbf{~ o x}}(\mathbf{K})$ & $\mathbf{T}_{\mathbf{a d}}(\mathbf{K})^{\mathbf{a}}$ & $\mathbf{X N}_{\mathbf{2}}{ }^{\mathbf{b}}$ & $\mathbf{X O}_{\mathbf{2}}{ }^{\mathbf{b}}$ & $\mathbf{X H}_{\mathbf{2}} \mathbf{O}^{\mathbf{b}}$ \\
\hline $\mathrm{CH}_{4}$ & 96.5 & 12000 & 0.029 & 0.465 & $4.8 \times 10^{-3}$ & 1490 & 1563 & 0.719 & 0.102 & 0.178 \\
$\mathrm{CH}_{4}$ & 96.5 & 12000 & 0.028 & 0.485 & $4.7 \times 10^{-3}$ & 1520 & 1603 & 0.716 & 0.097 & 0.185 \\
$\mathrm{CH}_{4}$ & 96.5 & 12000 & 0.027 & 0.506 & $4.5 \times 10^{-3}$ & 1540 & 1646 & 0.714 & 0.093 & 0.192 \\
$\mathrm{DME}$ & 78.3 & 38480 & 0.064 & 0.380 & $5.6 \times 10^{-3}$ & 1330 & 1372 & 0.731 & 0.120 & 0.148 \\
$\mathrm{C}_{3} \mathrm{H}_{8}$ & 72.5 & 34100 & 0.040 & 0.360 & $5.8 \times 10^{-3}$ & 1274 & 1326 & 0.730 & 0.128 & 0.141 \\
\hline
\end{tabular}

${ }^{\mathrm{a}}$ calculated with a reactant temperature of $290 \mathrm{~K}$

${ }^{\mathrm{b}}$ determined during data processing as described in Sec. 3.2 


\section{List of Figure Captions}

1. Schematic of high-energy, pulse burst laser system (HEPBLS) as used in the current experiments. The configuration depicted is a single-output, leg with six amplifier stages optimized for high-energy output. $\mathrm{PO}=$ pulsed oscillator; $\mathrm{OI}=$ optical isolator; $\mathrm{M}=$ mirror; $\mathrm{SL}=$ spherical lens; $\mathrm{DPH}=$ diamond pinhole; PBS = polarizing beam splitter cube; $\mathrm{QWP}=$ quarter-waveplate; HWP $=$ halfwaveplate; $\mathrm{BD}=$ beam dump; $\mathrm{PCM}=$ phase conjugate mirror; $\mathrm{VSF}=$ vacuum spatial filter; $\mathrm{QR}=90^{\circ}$ quartz rotator; $\mathrm{DC}=$ dichroic beam splitter

2. Example 532-nm pulse energy distribution within a single $20-\mathrm{ms}$ burst at $10 \mathrm{kHz}$. Note the trace presented was acquired with 5/6 amplifier stages (see Fig. 1) operating.

3. (a) Schematic of the high-speed imaging setup used for the auto-ignition experiments. (b) Photograph of a $\mathrm{Re}=38,480 \mathrm{DME}$ flame (1330 K oxidizer) under steady operating conditions.

4. Schematic of the DLR Jet-in-Hot-Coflow (JHC) burner.

5. Relationship between temperature $(T)$ and fuel mole fraction, $X_{f}$, for various fuel according to Eqs. (3) and (4). $\mathrm{T}_{\mathrm{ox}}=$ oxidizer temperature and $\mathrm{T}_{\mathrm{f}}=$ fuel temperature.

6. Results from a series of plug flow reactor (PFR) simulations showing the normalized fuel mole fraction $\left(\mathrm{X}_{\text {fuel }} / \mathrm{X}_{\text {fuel,o }}\right)$ as a function of mixture fraction/temperature and PFR residence time $\left(\tau_{\mathrm{R}}\right)$. A value of $X_{\text {fuel }} / X_{\text {fuel, },}=1$ indicates that no reaction of the fuel has taken place at a given time, $\tau_{R}$. The 'white, solid' contour is an estimated maximum residence time for the cold jet in hot coflow conditions at an axial position of $\mathrm{x} / \mathrm{d}=20$. The 'white, dotted' line represents the stoichiometric mixture fraction, $\xi_{s}$, value.

7. The solid lines represent the relationship between $\mathrm{S}_{\mathrm{RAY}} / \mathrm{S}_{\mathrm{air}}$ and the normalized mixture fraction $\left(\xi / \xi_{\mathrm{s}}\right)$ according to Eqs. (2) - (4). The dashed lines represent the relationship between $S_{\mathrm{RAY}} / \mathrm{S}_{\text {air }}$ and the normalized mixture fraction $\left(\xi / \xi_{\mathrm{s}}\right)$ under combustion conditions if the detected Rayleigh scattering signal was inversely proportional to temperature for a given value of $\xi$.

8. Estimated temperature error for the post-ignition assumption of $S_{\mathrm{RAY}} / \mathrm{S}_{\mathrm{air}}=\left(\mathrm{T} / \mathrm{T}_{\mathrm{air}}\right)^{-1}$ under "lean" conditions $\left(\xi<\xi_{\mathrm{s}}\right)$.

9. Hydrogen/air flame temperatures as a function of equivalence ratio: (symbols) measured temperatures according the experimental conditions of Table 1. (solid black line) adiabatic flame temperature, $\mathrm{T}_{\mathrm{ad}}$. (red, dashed line) $\mathrm{T}=0.95 * \mathrm{~T}_{\mathrm{ad}}(5 \%$ heat loss $)$.

10. Radial profiles of the oxidizer temperature (no jet flow) at an axial position of $x / d=20$ for three experimental cases shown in Table 1. The red line represents an instantaneous profile and the black line represents the average from 100 profiles. The 'dashed' line represents the adiabatic flame temperature, $\mathrm{T}_{\mathrm{ad}}$, and is shown for reference.

11. Probability density functions (pdf) of the measured oxidizer temperature for three experimental cases shown in Table 1. The pdf was constructed from a single, instantaneous image representing 15,000 data points over the spatial domain of $6<\mathrm{r} / \mathrm{d}<9$ and $17<\mathrm{x} / \mathrm{d}<23$. The standard deviation derived from each pdf is listed above the corresponding distribution. 
12. Time-series measurements (at a single spatial position) of temperature in the coflow for three difference oxidizer cases. The 'dashed' line corresponds to the average of each individual trace.

13. Normalized mixture fraction $\left(\xi / \xi_{\mathrm{cl}}\right)$ profiles as a function of normalized radial position $\left(\mathrm{r} / \mathrm{r}_{1 / 2}\right)$ at an axial position of $\mathrm{x} / \mathrm{d}=20$. The 'dashed' lines correspond to $\mathrm{T}=300 \mathrm{~K}$, non-reacting propane jets issuing into air. The 'solid' lines correspond to the fuel jets in hot, vitiated coflows as identified in Table 1. Note: all curves exhibit self-similarity and collapse upon one another.

14. Example 10-kHz image sequence of the transient fuel injection of $\mathrm{C}_{3} \mathrm{H}_{8}$ into a $\mathrm{T}=1270 \mathrm{~K}$ coflow at an axial position of $x / d=20$. The steady-state Reynolds number of the jet is 34,100 .

15. Example image sequences of the $10-\mathrm{kHz} \mathrm{OH}^{*} \mathrm{CL}$ fields. The top rows of each sequence correspond to the $\mathrm{OH}^{*}$ emission as viewed from $\mathrm{OH}^{*} \mathrm{CL}$ Camera 1 in Fig. 3a and the bottom rows correspond to the $\mathrm{OH}^{*}$ emission as viewed from $\mathrm{OH}^{*} \mathrm{CL}$ Camera 2 in Fig. 3a. (a) Initial kernel forms within the laser sheet used for planar Rayleigh scattering. (b) Initial kernel forms outside of the laser sheet.

16. Example 10-kHz image sequences of mixture fraction (top), $\mathrm{OH}^{*} \mathrm{CL}$ (middle), and temperature (bottom) for the case of $\mathrm{C}_{3} \mathrm{H}_{8}$ auto-igniting in a $\mathrm{T}=1270 \mathrm{~K}$ coflow. The circled regions correspond to the spatial location of the initial ignition kernel formation and subsequent displacement.

17. Example 10-kHz image sequences of mixture fraction (top), $\mathrm{OH}^{*} \mathrm{CL}$ (middle), and temperature (bottom) for the case of $\mathrm{CH}_{4}$ auto-igniting in a $\mathrm{T}=1490 \mathrm{~K}$ coflow. The circled regions correspond to the spatial location of the initial ignition kernel formation and subsequent displacement.

18. Example ten-frame, $10-\mathrm{kHz}$ image sequence of $\mathrm{OH}^{*} \mathrm{CL}$ (top) and temperature (bottom) for the case of DME auto-igniting in a $\mathrm{T}=1330 \mathrm{~K}$ co-flow. The circled regions correspond to the spatial location of the initial ignition kernel formation and subsequent displacement.

19. Example image sequence of the logarithm of the scalar dissipation rate for the case of DME autoigniting in a $\mathrm{T}=1330 \mathrm{~K}$ co-flow. The five images correspond to frames 2-6 of Fig. 18. Overlaid on the scalar dissipation rate layers are the stoichiometric mixture fraction contour $(\xi$ s, shown as blue solid line) and a $\mathrm{T}=1380 \mathrm{~K}$ iso-contour (red line) denoting the onset and initial displacement of the auto-ignition kernel. 


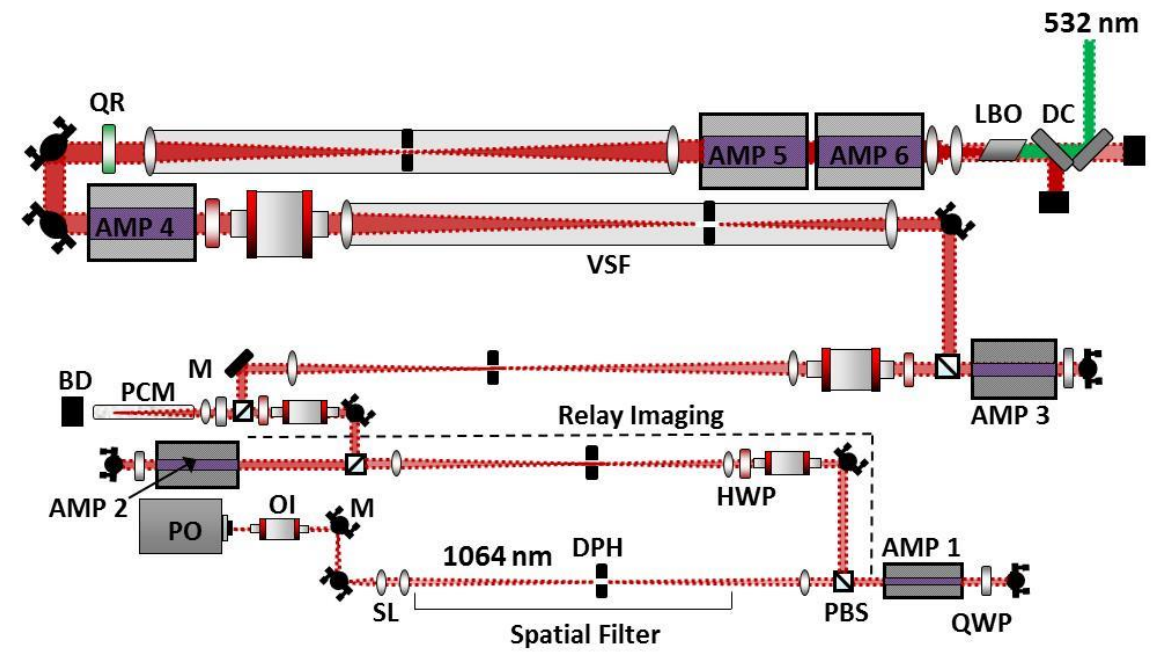

Figure 1 


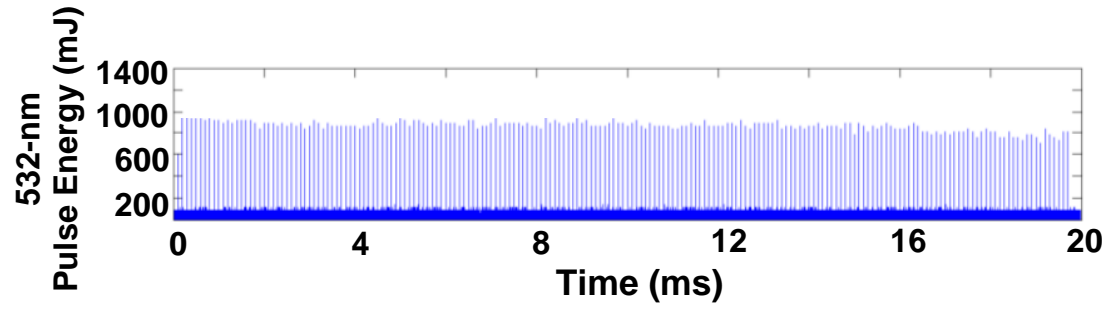

Figure 2 
(a)
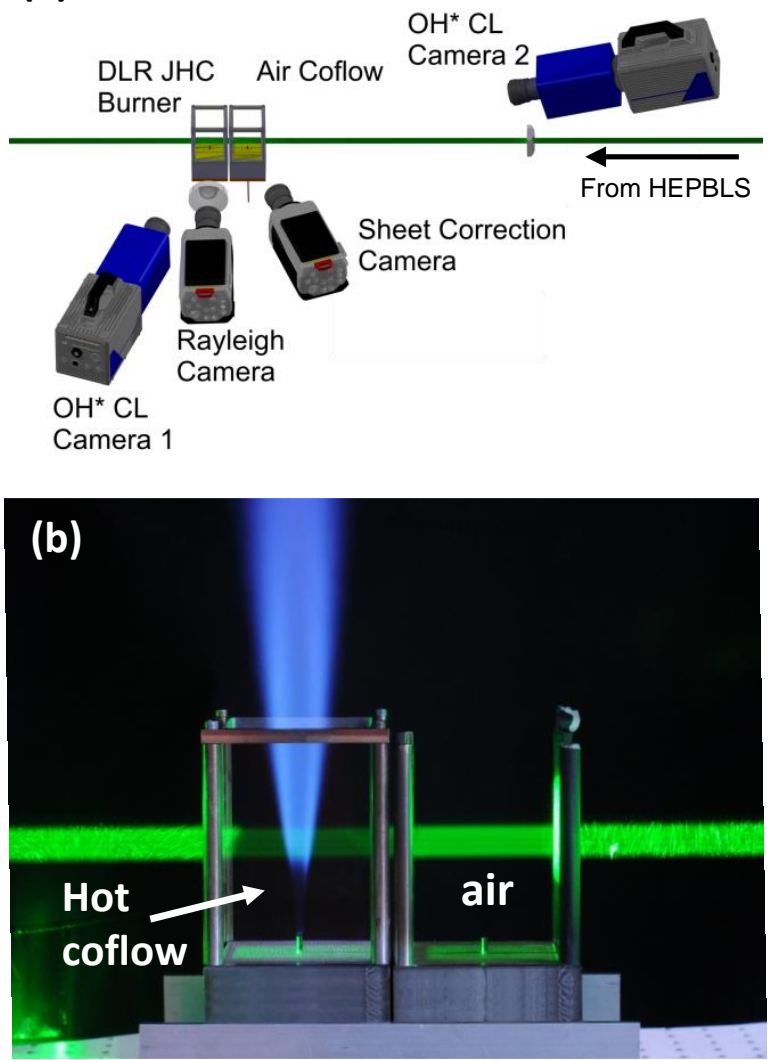

Figure 3 


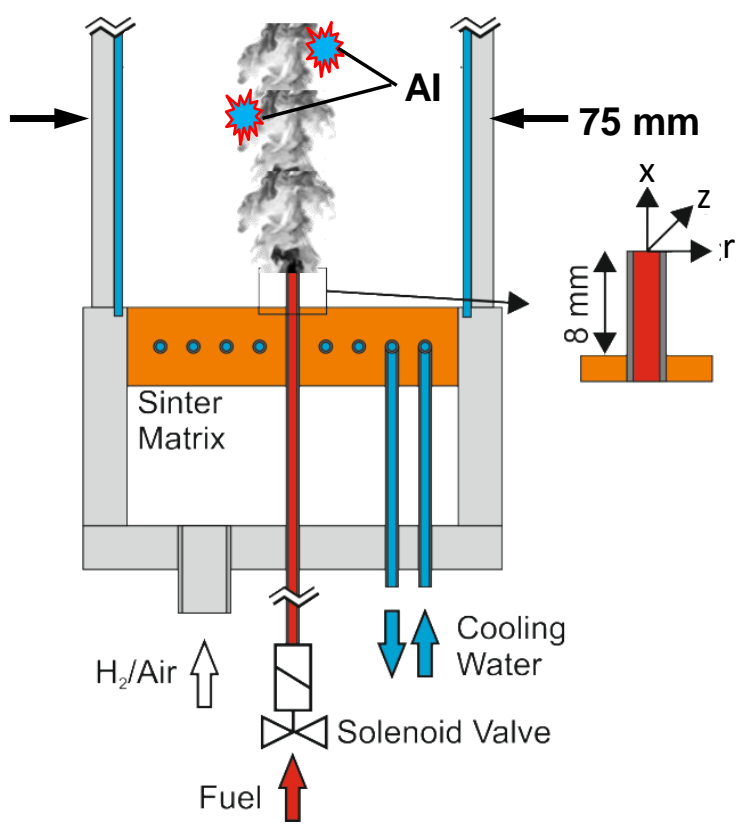

Figure 4 


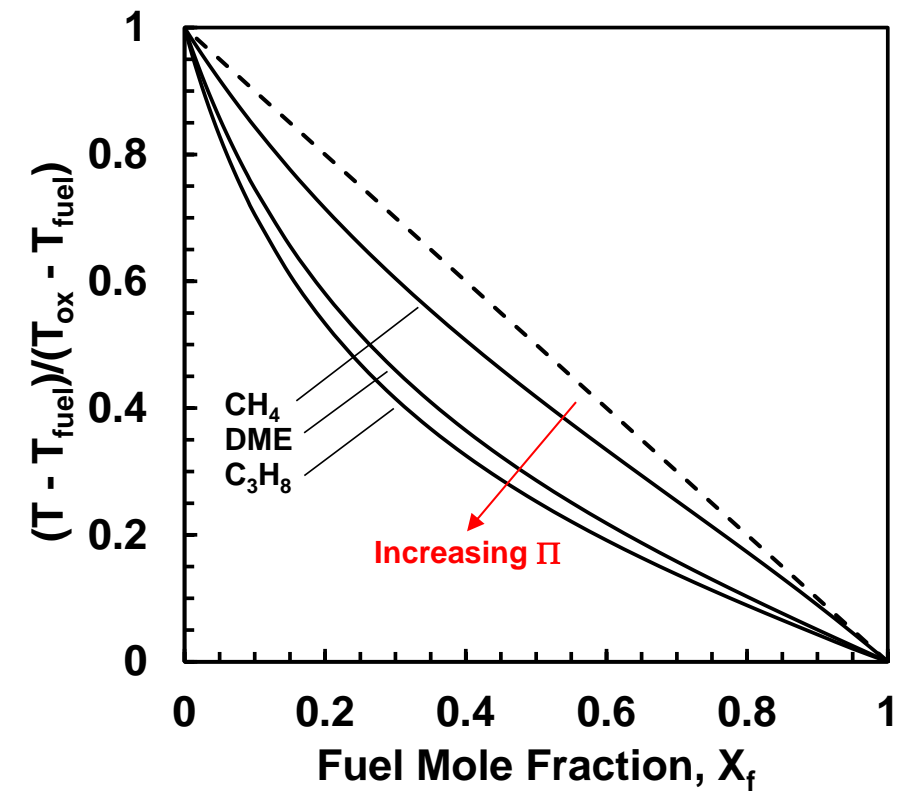

Figure 5 

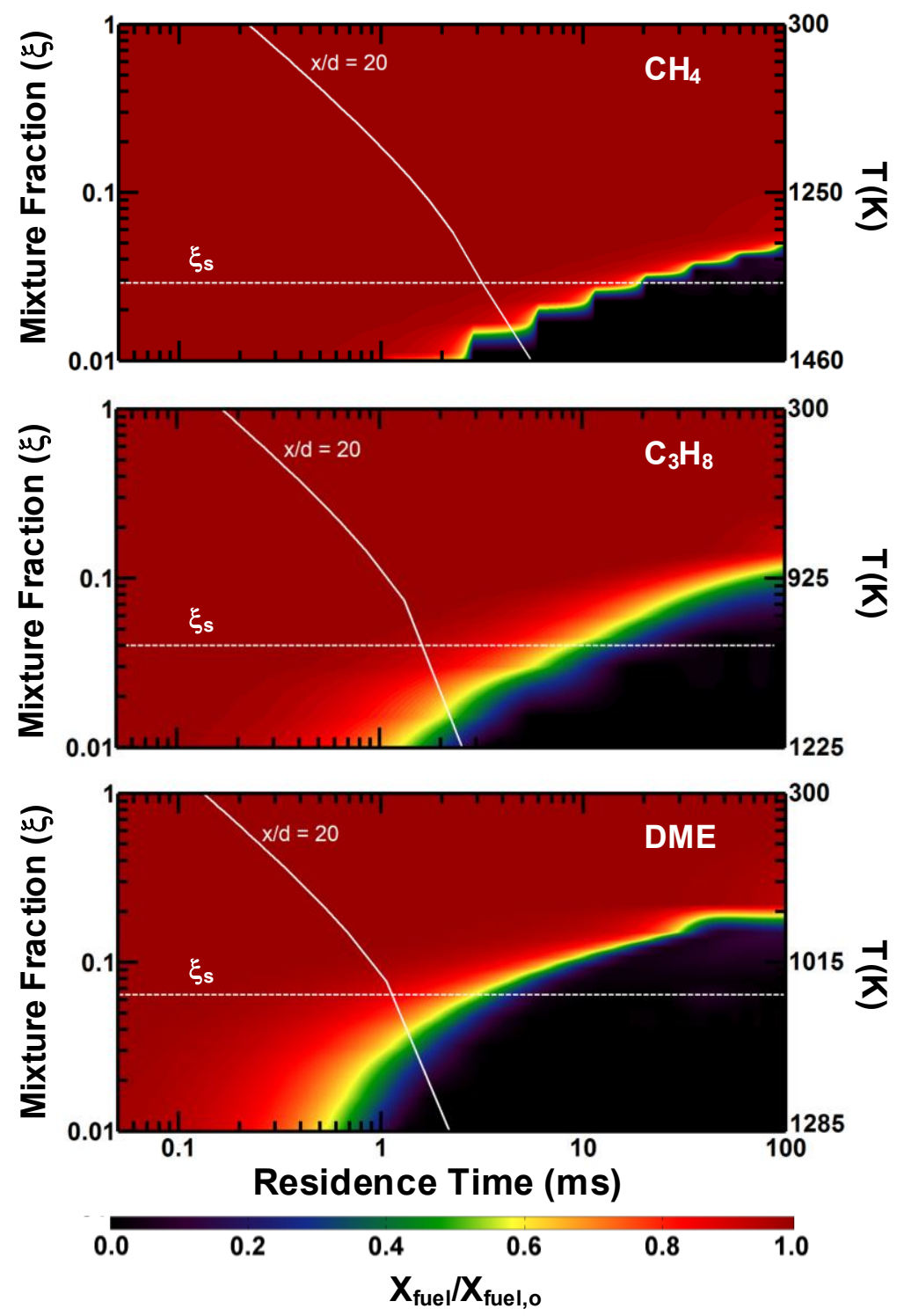

Figure 6 


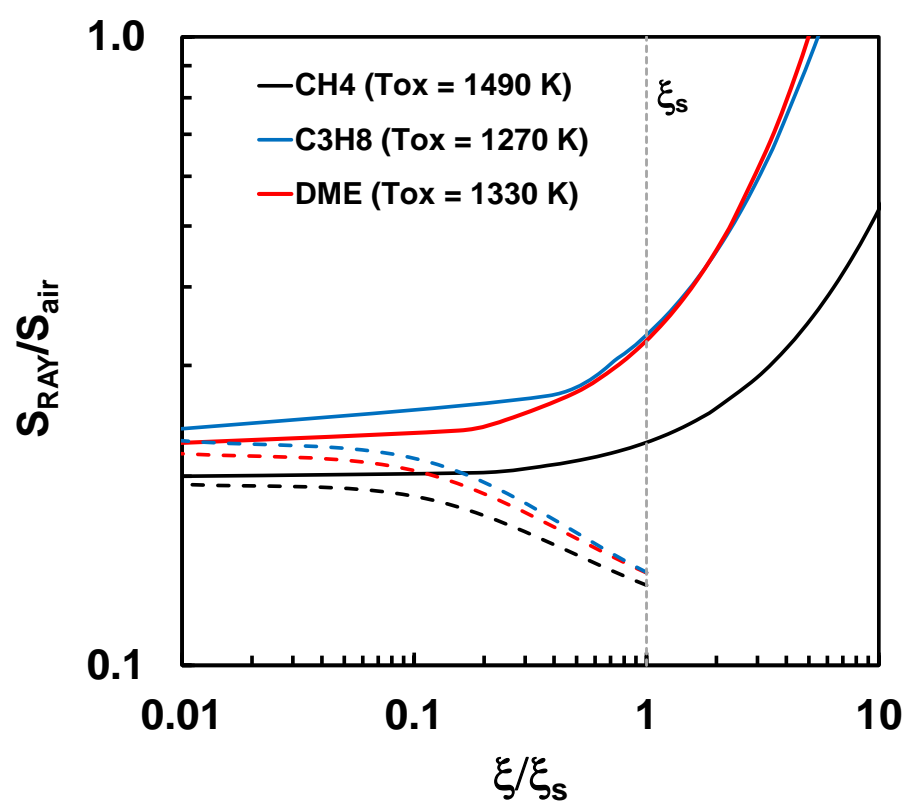

Figure 7 


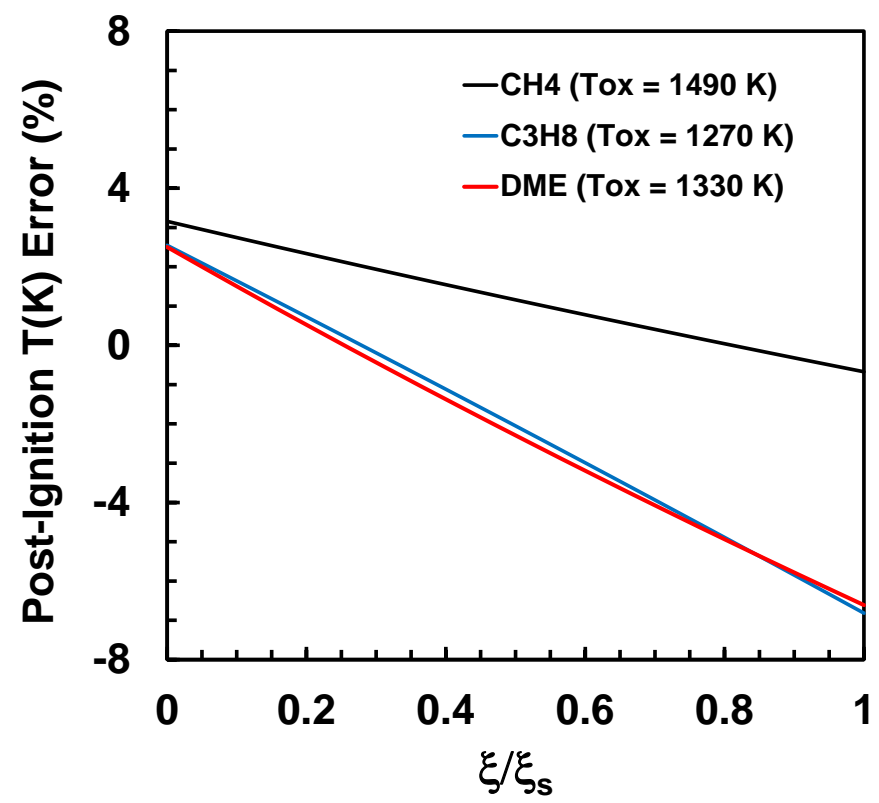

Figure 8 


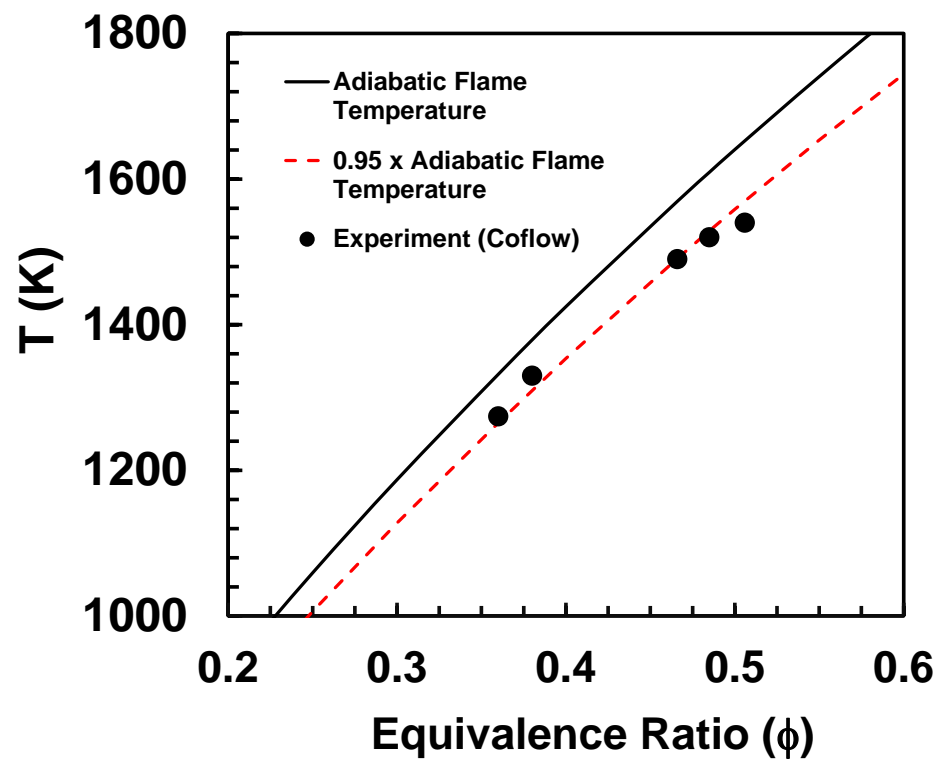

Figure 9 

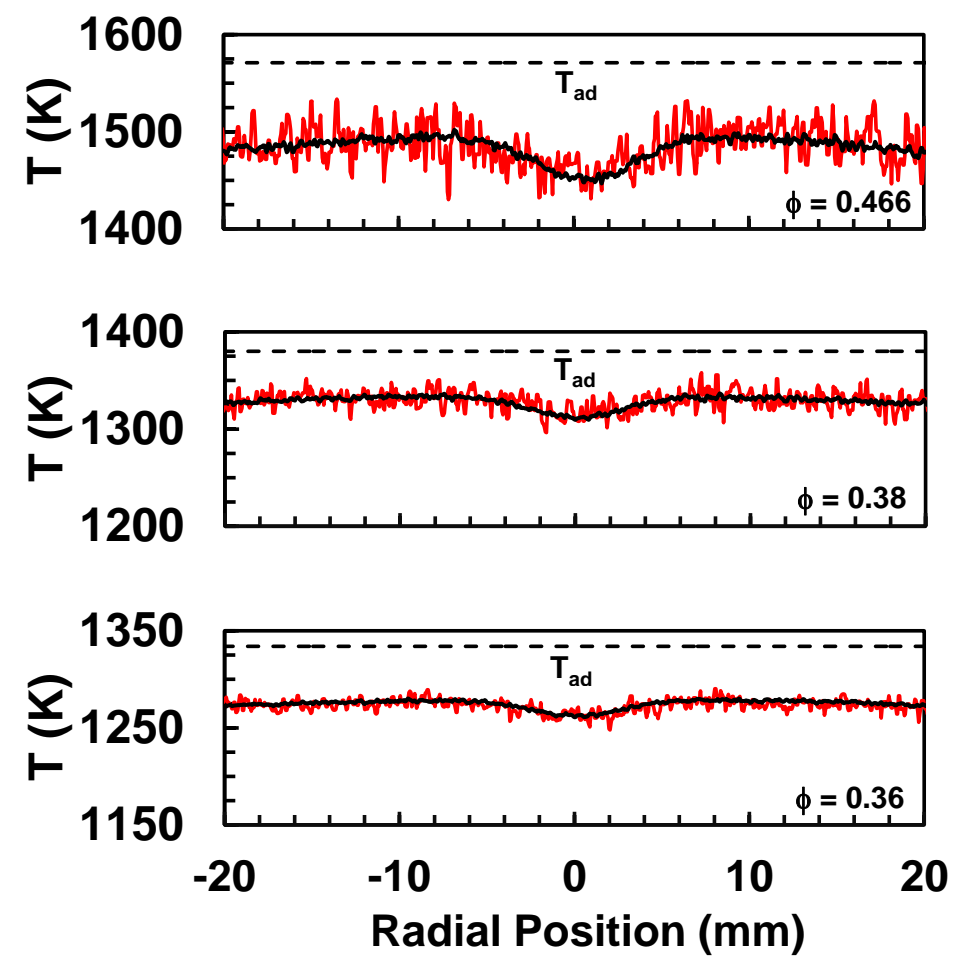

Figure 10 


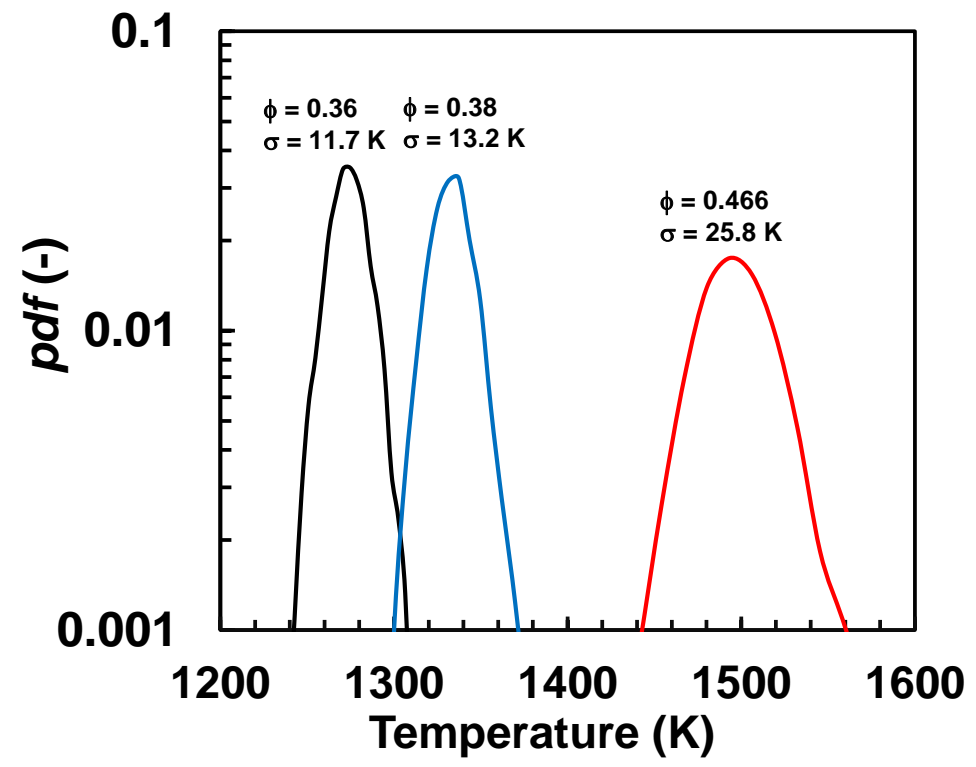

Figure 11 


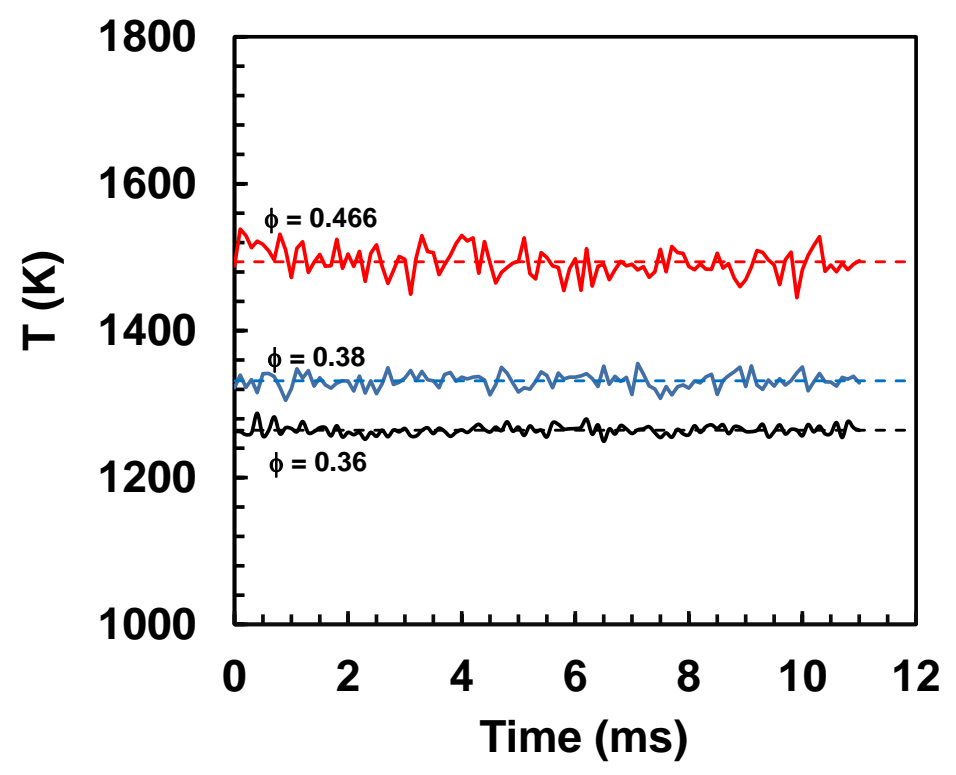

Figure 12 


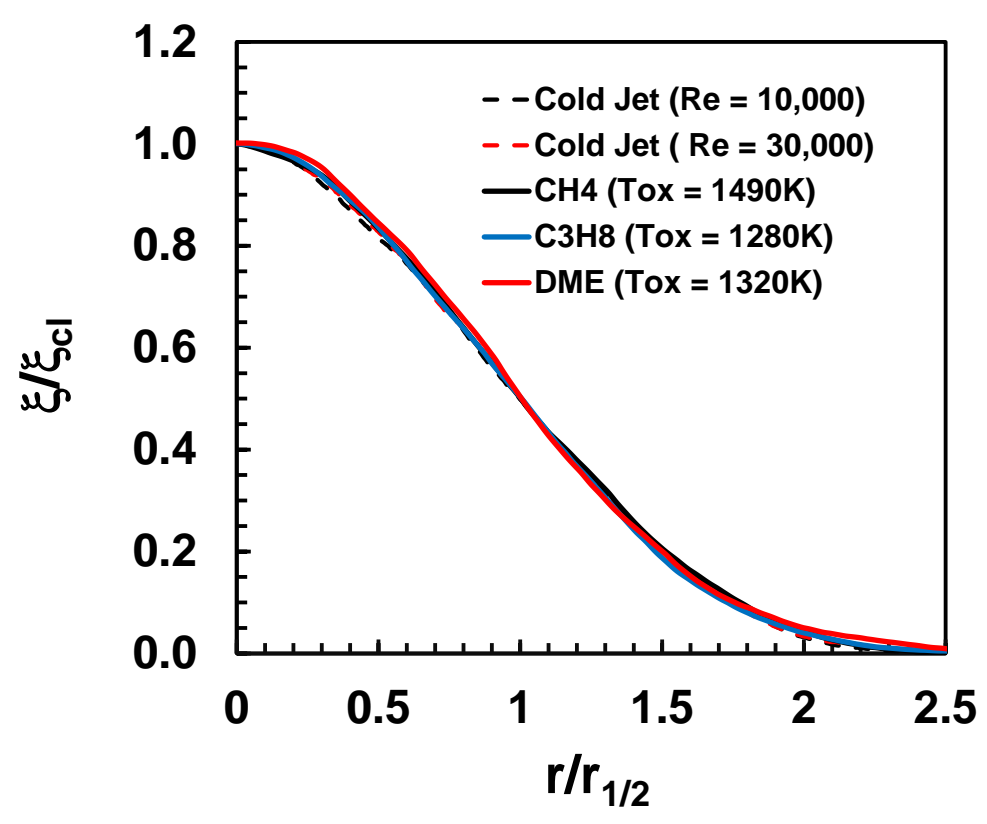

Figure 13 


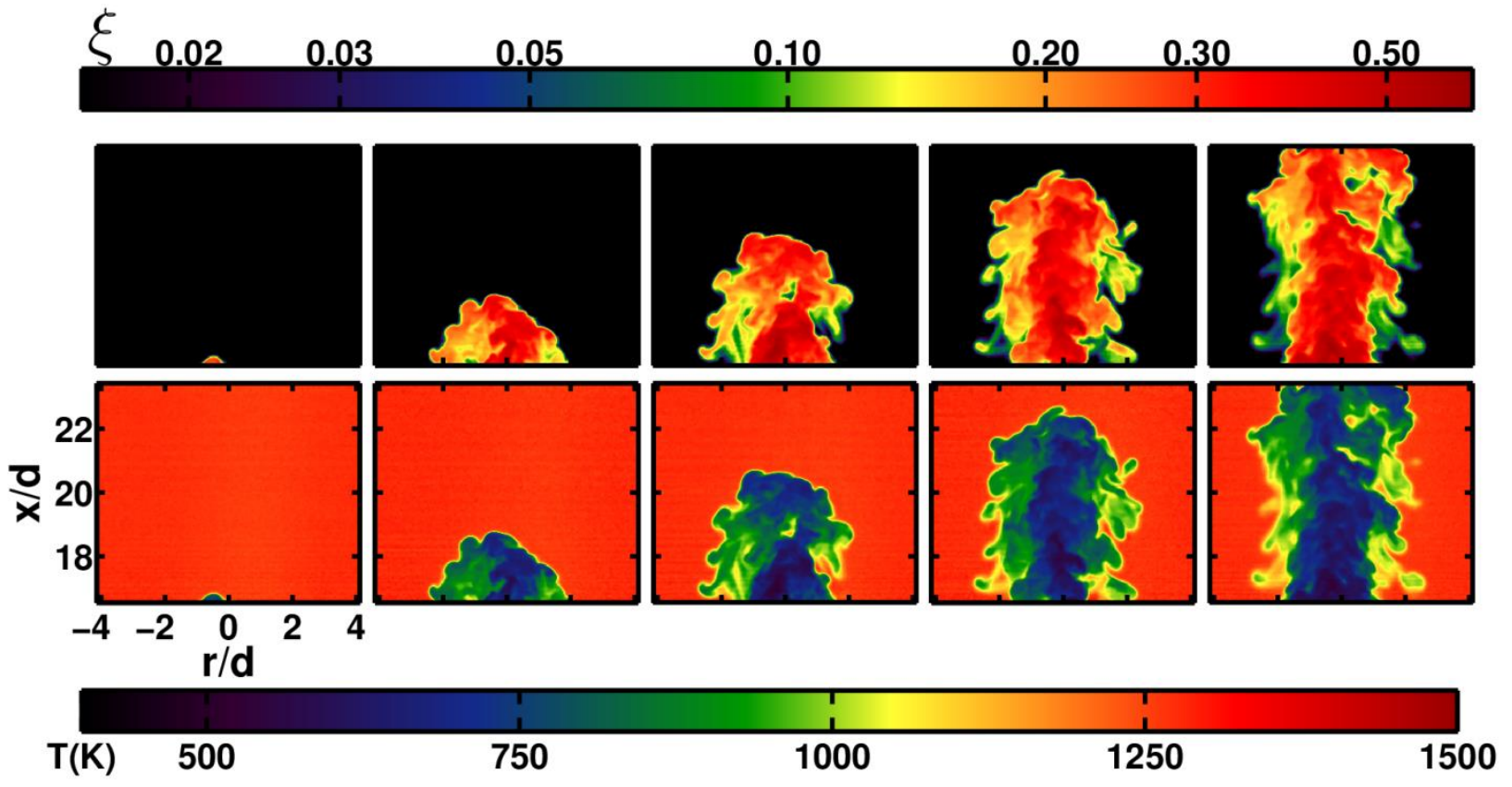

Figure 14 

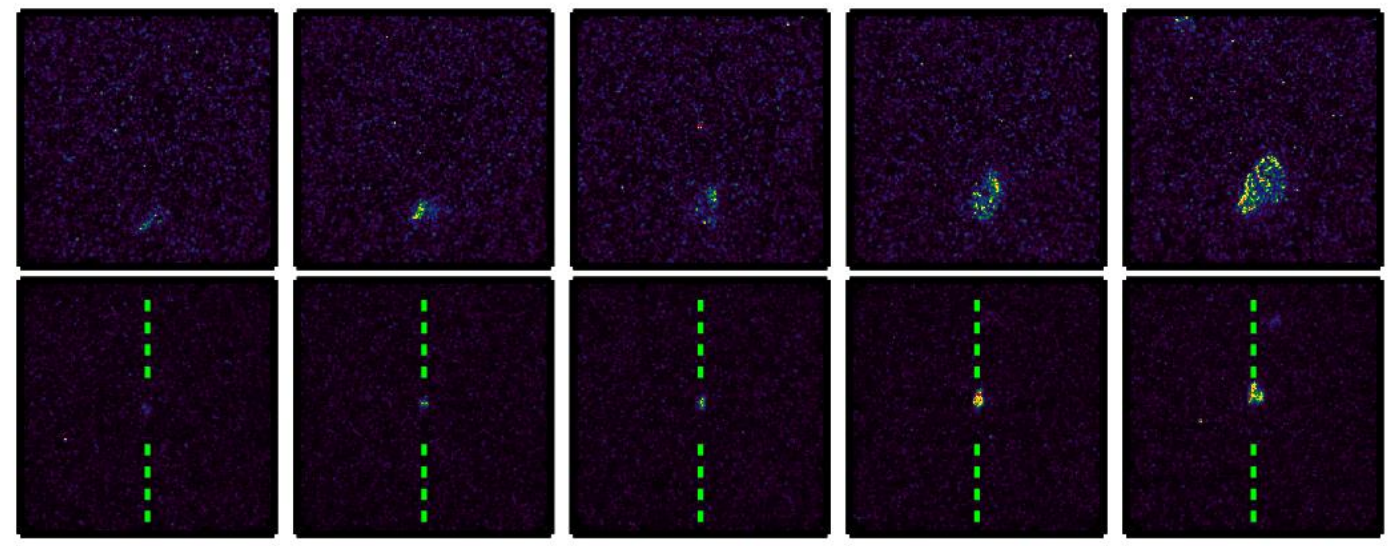

(a)
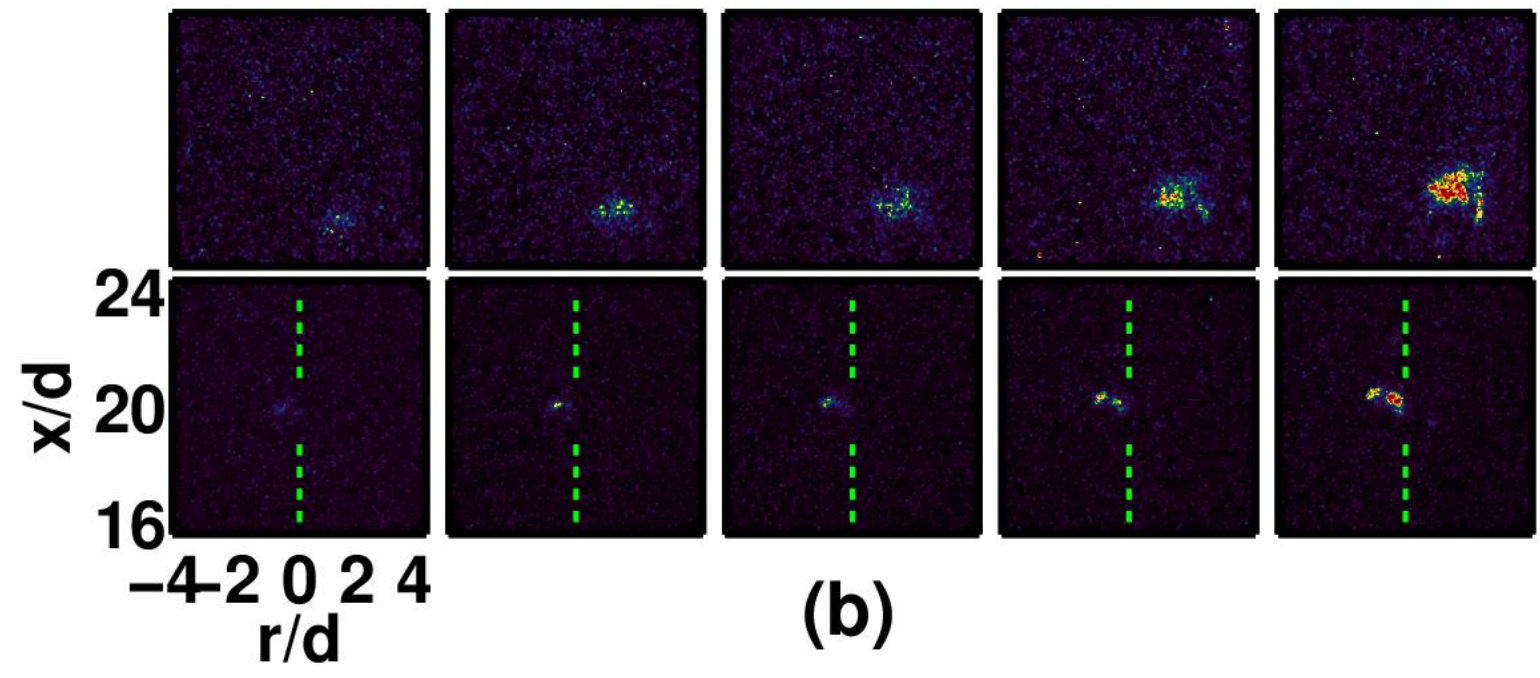

(b)

Figure 15 

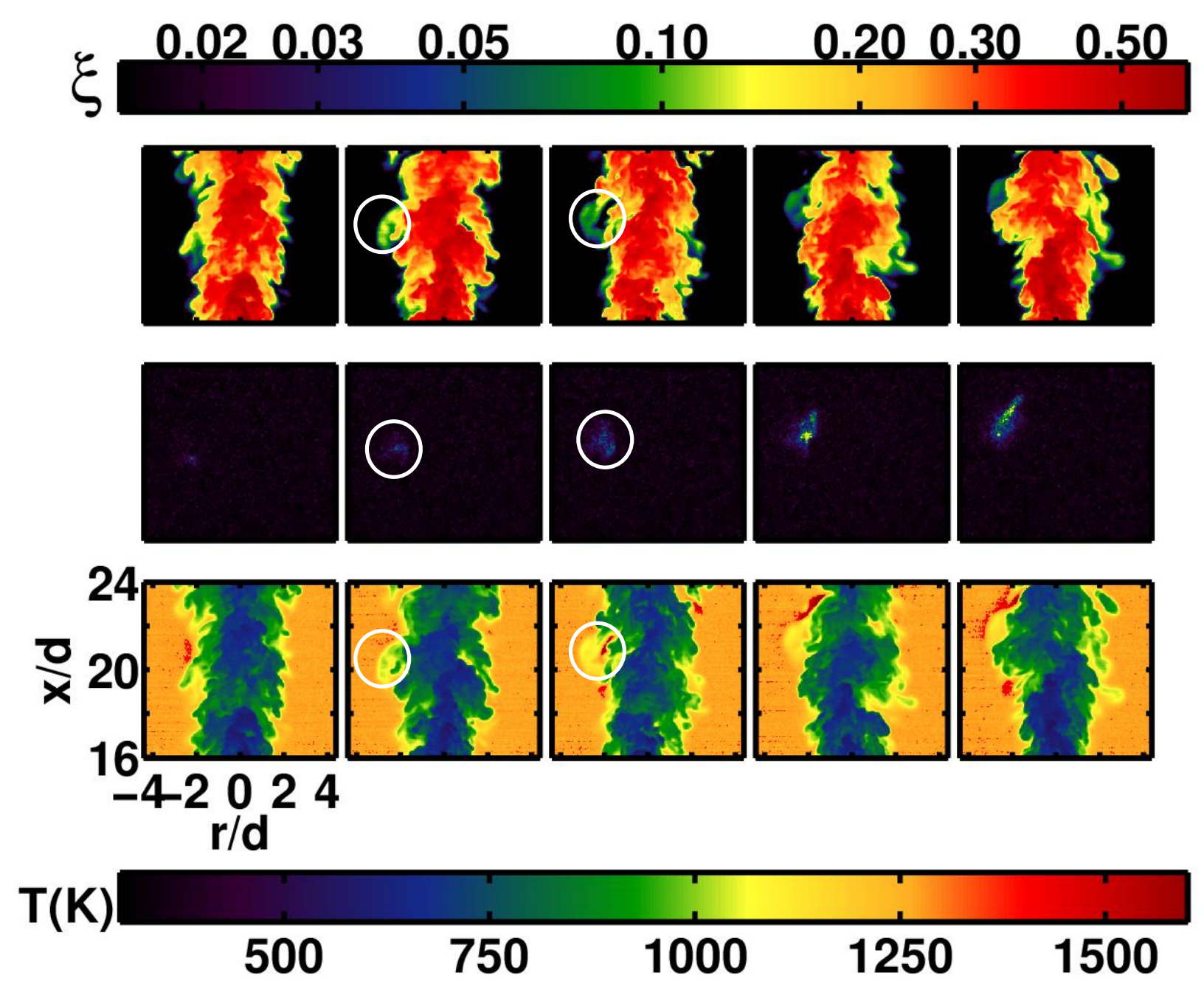

Figure 16 

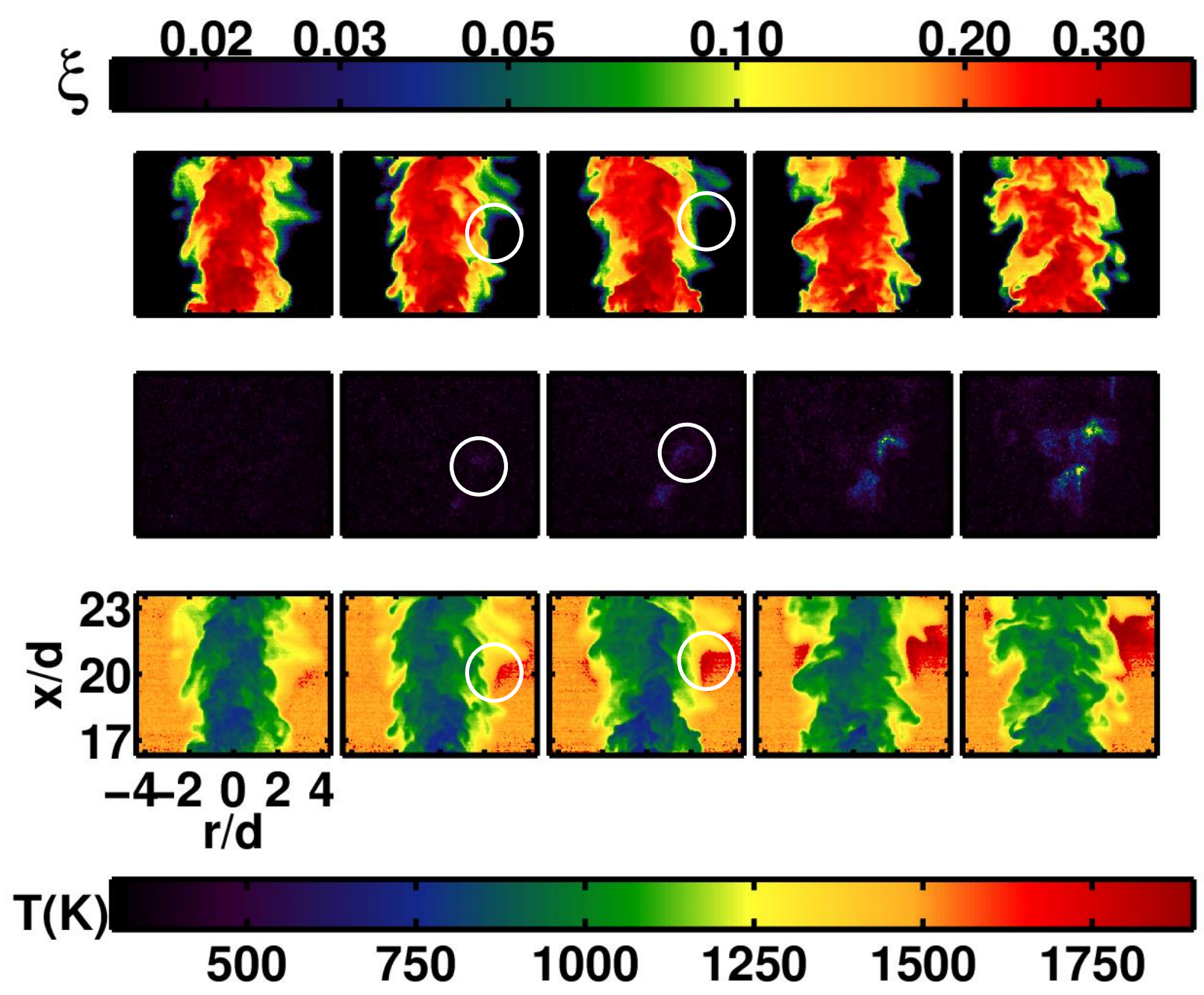

Figure 17 

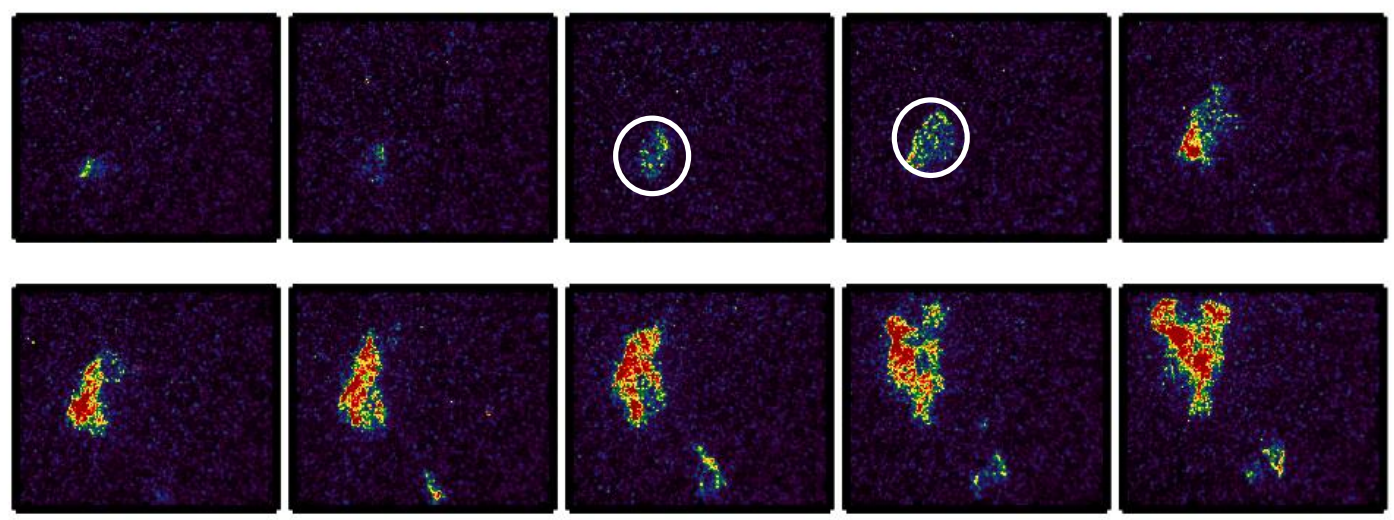

(a)
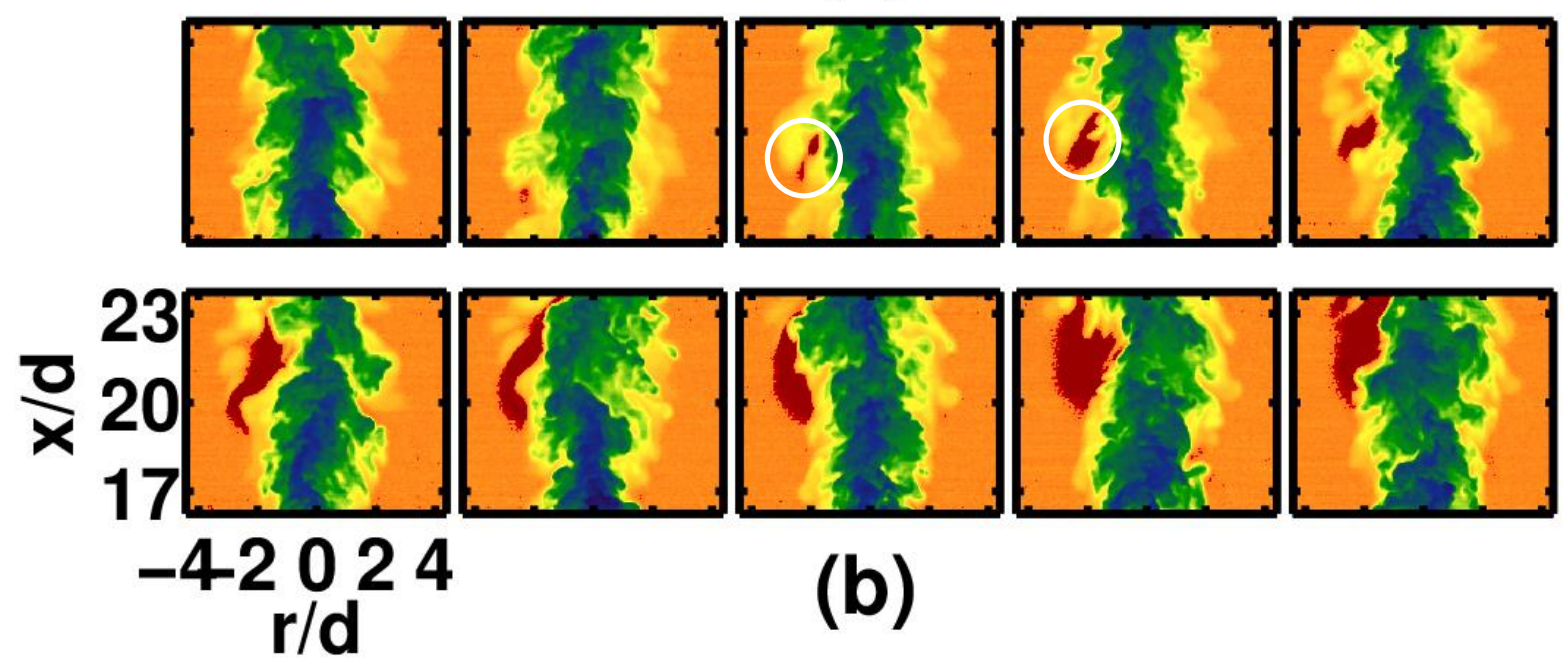

(b)

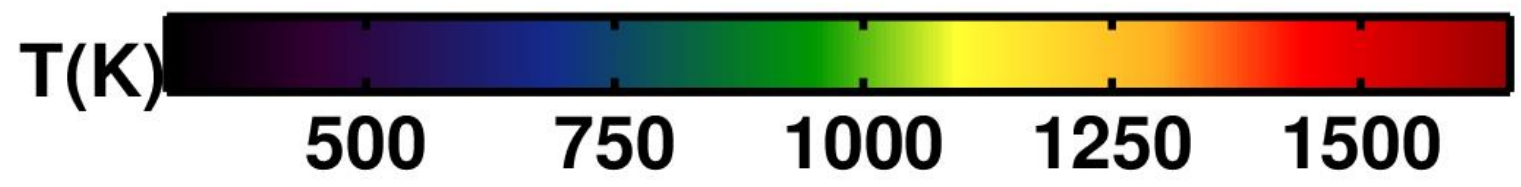

Figure 18 


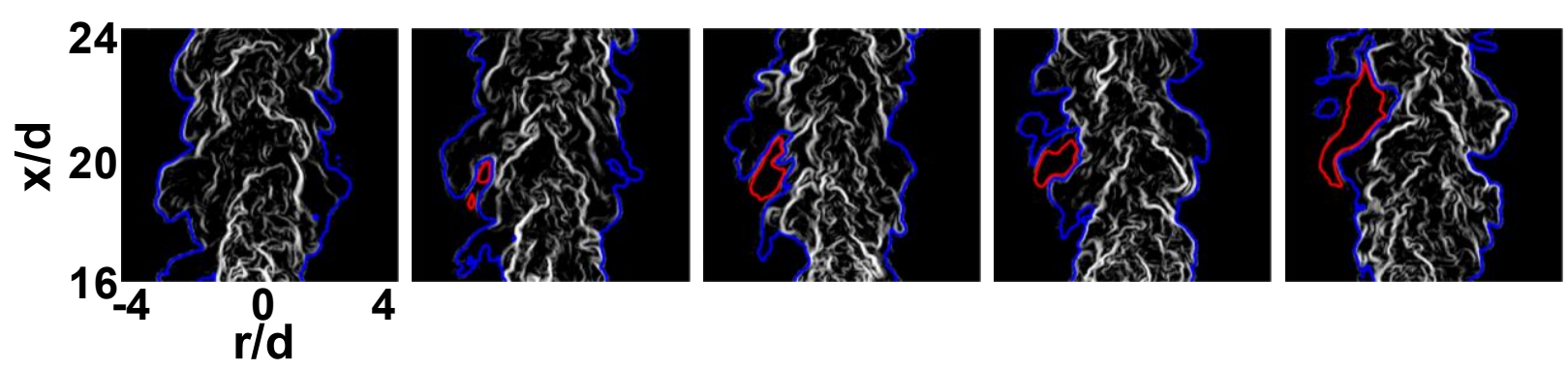

Figure 19 